\title{
Hypoxia-inducible factor 1 mediates TAZ expression and nuclear localization to induce the breast cancer stem cell phenotype
}

\author{
Lisha Xiang1,2,3, Daniele M. Gilkes ${ }^{2,3}$, Hongxia Hu2,3, Naoharu Takano ${ }^{2,3,5}$, Weibo \\ Luo $^{2,3}$, Haiquan Lu, L, $^{2}$, John W. Bullen ${ }^{2,3}$, Debangshu Samanta ${ }^{2,3}$, Houjie Liang ${ }^{1}$ and \\ Gregg L. Semenza ${ }^{2,3,4}$ \\ ${ }^{1}$ Department of Oncology and Southwest Cancer Center, Southwest Hospital, Third Military Medical University, Chongqing, \\ China \\ ${ }^{2}$ Vascular Program, Institute for Cell Engineering, Johns Hopkins University School of Medicine, Baltimore, MD \\ ${ }^{3}$ McKusick-Nathans Institute of Genetic Medicine, Johns Hopkins University School of Medicine, Baltimore, MD \\ ${ }^{4}$ Departments of Pediatrics, Medicine, Oncology, Radiation Oncology, and Biological Chemistry, Johns Hopkins University \\ School of Medicine, Baltimore, MD \\ ${ }^{5}$ Department of Biochemistry, School of Medicine, Keio University, Tokyo, Japan \\ Correspondence to: Gregg L. Semenza, email: gsemenza@jhmi.edu
}

Keywords: Aldefluor assay, basal-like breast cancer, mammospheres, targeted therapy, triple-negative breast cancer

Received: December 11,2014 Accepted: December 12, $2014 \quad$ Published: December 18, 2014

This is an open-access article distributed under the terms of the Creative Commons Attribution License, which permits unrestricted use, distribution, and reproduction in any medium, provided the original author and source are credited.

\section{ABSTRACT}

Intratumoral hypoxia, which is associated with breast cancer metastasis and patient mortality, increases the percentage of breast cancer stem cells (BCSCs) but the underlying molecular mechanisms have not been delineated. Here we report that hypoxia-inducible factor 1 (HIF-1) triggers the expression and activity of TAZ, a transcriptional co-activator that is required for BCSC maintenance, through two discrete mechanisms. First, HIF-1 binds directly to the WWTR1 gene and activates transcription of TAZ mRNA. Second, HIF-1 activates transcription of the SIAH1 gene, which encodes a ubiquitin protein ligase that is required for the hypoxia-induced ubiquitination and proteasome-dependent degradation of LATS2, a kinase that inhibits the nuclear localization of TAZ. Inhibition of HIF-1a, TAZ, or SIAH1 expression by short hairpin RNA blocked the enrichment of BCSCs in response to hypoxia. Human breast cancer database analysis revealed that increased expression (greater than the median) of both TAZ and HIF-1 target genes, but neither one alone, is associated with significantly increased patient mortality. Taken together, these results establish a molecular mechanism for induction of the BCSC phenotype in response to hypoxia.

\section{INTRODUCTION}

Breast cancer mortality occurs in patients whose cancer cells metastasize to distant sites, such as the lungs, bones, and brain. Individual cells must reach the site of metastasis and proliferate to form a secondary tumor. Only a small percentage of the cancer cells in a primary breast tumor have self-renewal capacity, which is necessary to form a metastasis or recurrent tumor, and are designated as tumor initiating cells or cancer stem cells (CSCs). Several different assays identify subpopulations of cells that are enriched for breast CSCs (BCSCs). The Aldefluor assay is based on the activity in BCSCs of the ALDH1 family of aldehyde dehydrogenases, which convert a nonfluorescent substrate into a fluorescent product that can be identified by flow cytometry [1-3]. The mammosphere assay is based on the ability of BCSCs to propagate as multicellular spheroids in suspension culture $[4,5]$. Flow cytometric identification of $\mathrm{CD} 44^{\text {high }} / \mathrm{CD} 24^{\text {low }}$ cells is a useful measure of BCSCs in luminal-type breast cancer but not in basal-like breast cancer cell lines, which express CD44 at high levels [6]. Both $\mathrm{ALDH}^{+}$and mammosphereforming cells are highly enriched for tumor-initiating BCSCs [1-6].

Several transcription factors have been implicated in the BCSC phenotype. TAZ (transcriptional co-activator 
with PDZ binding motif) is an effector of the Hippo pathway [7] that interacts with DNA binding proteins of the TEAD (TEA/ATTS domain) family to activate transcription of target genes, including CTGF, SERPINE1, and BIRC5, which encode connective tissue growth factor, plasminogen activator inhibitor 1 (PAI-1), and survivin, respectively [8-11]. TAZ is expressed in $80 \%$ of highgrade breast cancers and promotes BCSC self-renewal and tumor initiation capacity [10]. Amplification of the WWTR1 gene, which encodes TAZ mRNA, was identified in less than $10 \%$ of breast cancers, suggesting that other mechanisms must account for increased TAZ mRNA expression in the majority of cases. TAZ is also regulated post-translationally, as phosphorylation of TAZ by the kinase LATS1 or LATS2 blocks its nuclear localization and transcriptional activity [7] and it is not clear whether or how inhibition by LATS $1 / 2$ is down-regulated in breast cancer.

Hypoxia has been shown to induce the CSC phenotype in glioma [12] and breast cancer [3, 13] through the activity of hypoxia-inducible factors (HIFs). HIF transcriptional activity is constitutively increased in mouse lymphoma and human acute myeloid leukemia CSCs, which were eliminated by treatment with a HIF-1 inhibitor [14]. HIFs are also required for the maintenance of hematopoietic stem cells [15] and for the reprogramming of differentiated human cells to induced pluripotent stem cells [16]. However, the molecular mechanisms by which HIFs contribute to the stem cell phenotype have not been determined.

HIFs are heterodimers composed of an $\mathrm{O}_{2}$-regulated HIF-1 $\alpha$ or HIF- $2 \alpha$ subunit and a constitutively expressed HIF-1ß subunit [17]. HIF-1 $\alpha$ and HIF-2 $\alpha$ are subject to prolyl hydroxylation, ubiquitination, and proteasomal degradation under normoxic conditions, whereas hydroxylation is inhibited under hypoxic conditions, leading to rapid accumulation of HIF- $1 \alpha$ and HIF-2 $\alpha$, dimerization with HIF-1ß, and transcriptional activation of a large battery of target genes. The increase in $\mathrm{ALDH}^{+}$ BCSCs observed after exposure of cells to hypoxia was lost in subclones in which HIF-1 $\alpha$ expression was silenced by short hairpin RNA (shRNA), whereas HIF-2 $\alpha$ loss-offunction had no effect [3]. Overexpression of HIF-1 $\alpha$ in breast cancer is associated with increased patient mortality and HIF target genes play critical roles in angiogenesis, migration, invasion, and metastasis to lymph nodes, lungs, and bone [18-30]. The basal-like breast cancer transcriptional profile is characterized by increased expression of HIF target genes [31]. Here we delineate molecular mechanisms by which HIF-1-dependent activation of TAZ expression and activity induces the BCSC phenotype in response to hypoxia.

\section{RESULTS}

\section{Hypoxia induces HIF-1-dependent expression of TAZ}

Gene expression data from 1,160 human breast cancer specimens in the TCGA database were used to compare levels of TAZ mRNA with the expression of CXCR3, L1CAM, LOX, P4HA1, P4HA2, PDGFB, PLOD1, PLOD2, SLC2A1, and VEGFA mRNA, which are all HIF-regulated in breast cancer cells (Fig. S1A). Statistical analysis revealed that TAZ expression was significantly correlated with 8 out of 10 HIF-1 target genes (Fig. S1B). A HIF metagene signature, based on the combined expression of all $10 \mathrm{HIF}-1$ target genes, was also correlated with TAZ mRNA expression (Fig. S1C). These data suggest that TAZ mRNA expression may be HIF-regulated in human breast cancers, particularly in basal-like breast cancers.

To determine whether TAZ expression is induced by hypoxia, TAZ mRNA and protein levels were analyzed in immortalized but non-tumorigenic MCF10A mammary epithelial cells, tumorigenic but non-metastatic MCF7 and HCC-1954 breast cancer cells, and metastatic MDA-MB-231 and MDA-MB-435 breast cancer cells, which were exposed to non-hypoxic $\left(20 \% \mathrm{O}_{2}\right)$ or hypoxic $\left(1 \% \mathrm{O}_{2}\right)$ conditions for $24 \mathrm{~h}$. Reverse transcription (RT) and quantitative real-time PCR (qPCR) assays revealed that the expression of TAZ mRNA under non-hypoxic conditions was greatly increased in the two metastatic basal-like lines compared to the other breast cell lines, but expression was significantly induced by hypoxia in all 5 lines (Fig. 1A and Fig. S1D). TAZ protein was also highly expressed in the metastatic lines at $20 \% \mathrm{O}_{2}$ and its expression was induced by hypoxia in all cell lines assayed (Fig. 1B). To analyze TAZ expression in vivo, we injected MDA-MB-231 cells into the mammary fat pad of female severe combined immunodeficiency (SCID) mice. Immunohistochemistry of tumor sections revealed intense HIF- $1 \alpha$ staining in perinecrotic (hypoxic) regions, which co-localized with TAZ and with P4HA1, which is a known HIF-1 target gene product (Fig. S1E).

To determine whether HIF- $1 \alpha$ or HIF- $2 \alpha$ was required for TAZ expression under hypoxic conditions, we analyzed MDA-MB-231 and MCF-7 subclones, which were stably transfected with an expression vector encoding short hairpin RNA (shRNA) targeting HIF-1 $\alpha$ $(\operatorname{sh} 1 \alpha)$ or HIF- $2 \alpha(\operatorname{sh} 2 \alpha)$ or a non-targeting control shRNA (NTC), and MDA-MB-435 subclones, which were stably transfected with an empty vector $(\mathrm{EV})$ or expression vector encoding shRNA targeting HIF-1 $\alpha(\operatorname{sh} 1 \alpha)$ or HIF- $2 \alpha(\operatorname{sh} 2 \alpha)[21]$. Hypoxic induction of TAZ mRNA expression was lost in MDA-MB-231, MDA-MB-435 and MCF-7 cells when HIF-1 $\alpha$ (but not HIF-2 $\alpha$ ) was silenced 


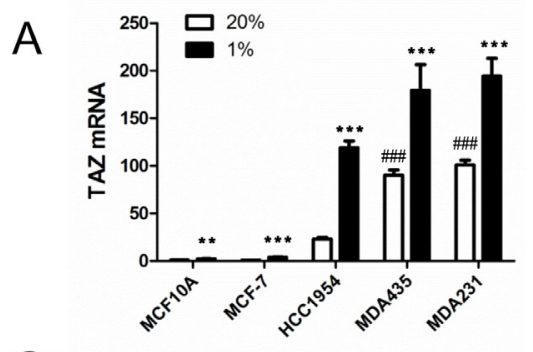

B
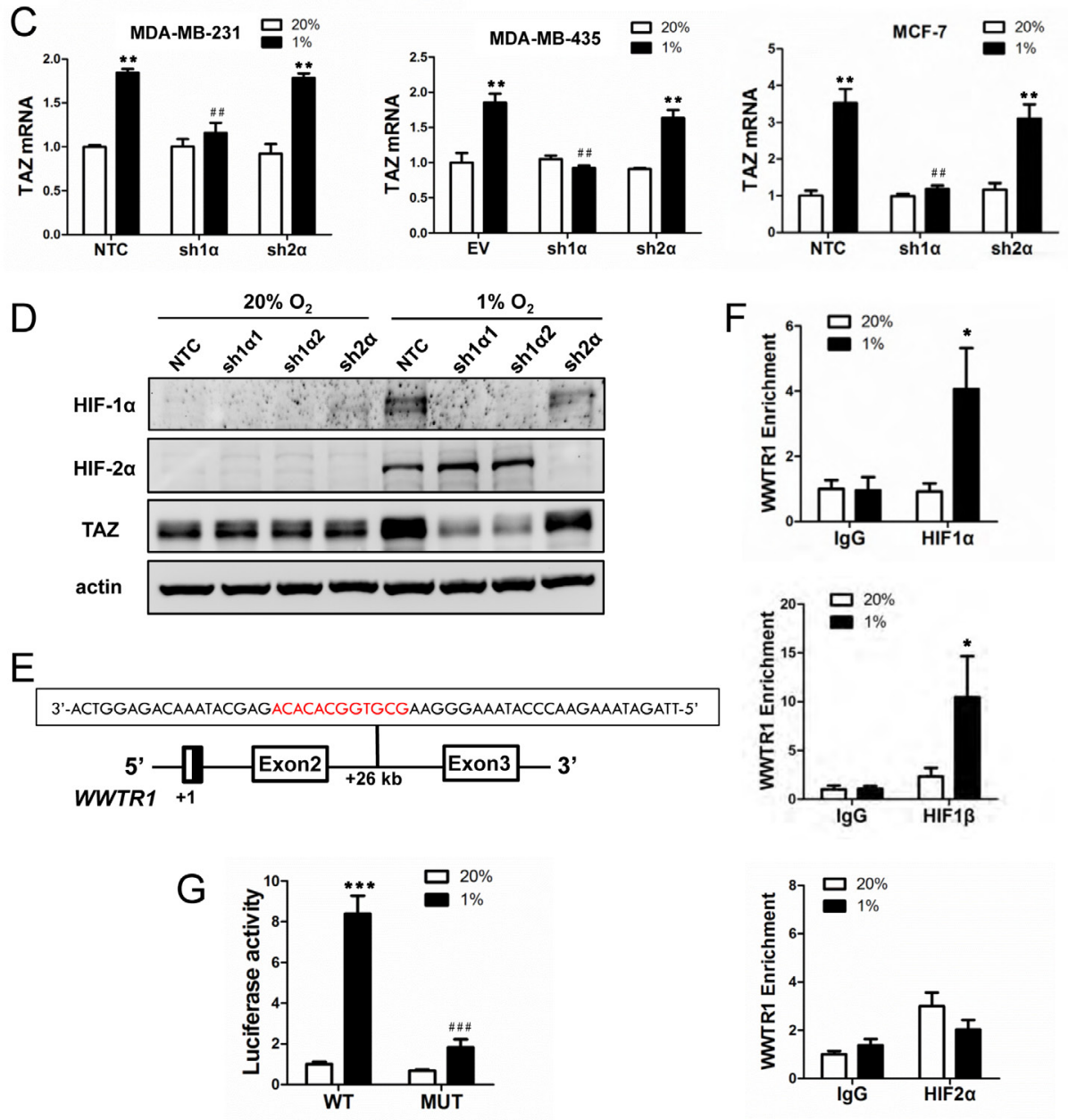

Figure 1: The WWTR1 gene encoding TAZ is a HIF-1 target gene. (A) Reverse transcription and quantitative real-time PCR (RT-qPCR) were performed to quantify TAZ mRNA levels in 5 breast cell lines following exposure to $20 \%$ or $1 \% \mathrm{O}_{2}$ for $24 \mathrm{~h}$. For each sample, the expression of TAZ mRNA was quantified relative to $18 \mathrm{~S}$ rRNA and then normalized to lane 1 (mean $\pm \mathrm{SEM} ; \mathrm{n}=3$ ). ${ }^{* *} P<0.01$,

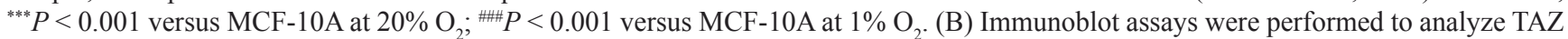
protein expression in breast cell lines following exposure to $20 \%(\mathrm{~N})$ or $1 \%(\mathrm{H}) \mathrm{O}_{2}$ for $48 \mathrm{~h}$. (C) TAZ mRNA expression was analyzed by RT-qPCR in the MDA-MB-231 (left), MDA-MB-435 (middle) and MCF-7 (right) non-targeting control (NTC) or empty vector (EV) subclone and subclones expressing shRNA targeting HIF-1 $\alpha(\operatorname{sh} 1 \alpha)$ or HIF- $2 \alpha(\operatorname{sh} 2 \alpha)$, which were exposed to $20 \%$ or $1 \% \mathrm{O}_{2}$ for 24 h. Data were normalized to lane 1 in each bar graph (mean $\pm \mathrm{SEM} ; \mathrm{n}=3$ ). ${ }^{* *} P<0.01$ versus NTC or EV at $20 \% \mathrm{O}_{2} ;{ }^{* \# P} P<0.01$ versus NTC or $\mathrm{EV}$ at $1 \% \mathrm{O}_{2}$. (D) Immunoblot assays were performed to analyze HIF-1 $\alpha$, HIF-2 $\alpha$, TAZ, and actin protein expression using lysates prepared from MDA-MB-231 subclones exposed to $20 \%$ or $1 \% \mathrm{O}_{2}$ for $48 \mathrm{~h}$. (E) The nucleotide sequence (non-coding strand) of a hypoxia response element (HRE; 5'-GCGTG-3' HIF-1 binding site and 5'-CACA-3' accessory sequence are shown in red) within intron 2 of the WWTR1 gene, located $26 \mathrm{~kb}$ from the transcription start site, is shown. Exons and intron are not drawn to scale. (F) HCC-1954 cells were exposed to $20 \%$ or $1 \% \mathrm{O}_{2}$ for $16 \mathrm{~h}$ and chromatin immunoprecipitation (ChIP) assays were performed using IgG or antibodies against HIF-1 $\alpha$ (upper panel), HIF-1 $\beta$ (middle panel), or HIF-2 $\alpha$ (lower panel). Primers flanking the HRE were used for qPCR and results were normalized to lane 1 (mean $\pm \mathrm{SEM} ; \mathrm{n}=3$ ). ${ }^{*} P<0.05$ versus $20 \% \mathrm{O}_{2}$ (Student's $t$ test). (G) The WWTR1 HRE containing a wild type (WT: 5'-GCGTG-3') or mutant (MUT; 5'-GAAAG-3') HIF-1 binding site was inserted into pGL2-Promoter (encoding firefly luciferase) and co-transfected with pSV-Renilla (encoding Renilla luciferase) into HCC-1954 cells, which were incubated at $20 \%$ or $1 \% \mathrm{O}_{2}$ for $24 \mathrm{~h}$. The firefly:Renilla luciferase ratio (Luciferase activity) was normalized to lane 1 (mean $\pm \mathrm{SEM} ; \mathrm{n}=3$ ). ${ }^{* * *} P<0.001$ versus WT at $20 \% \mathrm{O}_{2} ;{ }^{*{ }^{*}} P<0.001$ versus WT at $1 \% \mathrm{O}_{2}$ (Student's $t$ test). 
(Fig. 1C). Hypoxic induction of TAZ protein expression was also abrogated by two different shRNAs $(\operatorname{sh} 1 \alpha 1$ and sh1 $\alpha 2$ ) targeting HIF-1 $\alpha$ (Fig. 1D).

In previous analyses of several other HIF-1 target genes, we identified HREs that contained a match to the HIF binding site consensus 5'-RCGTG-3' followed after 1 to 8 bp by $5^{\prime}$-CACA-3' [32]. Analysis of the human WWTR1 gene, which encodes TAZ, revealed the sequence 5'-GCGTGGCACACA-3' on the antisense strand within intron 2, at a distance of $26 \mathrm{~kb} \mathrm{3}$ ' to the transcription start site (Fig. 1E). To determine whether HIF-1 binds at this site, chromatin immunoprecipitation (ChIP) assays were performed in HCC-1954 breast cancer cells, which demonstrated hypoxia-inducible binding of HIF- $1 \alpha$ and HIF-1 $1 \beta$, but not HIF-2 $\alpha$, at this site (Fig. 1F). To test whether this putative HRE was functional, a 55-bp oligonucleotide spanning the HIF-1 binding site (Fig. 1E) was inserted into the reporter plasmid pGL2promoter, in which a basal SV40 promoter drives firefly luciferase expression. HCC-1954 cells were co-transfected with pGL2/WWTR1-HRE and pSV-Renilla, in which the basal SV40 promoter drives Renilla luciferase expression, and exposed to $20 \%$ or $1 \% \mathrm{O}_{2}$ for $24 \mathrm{~h}$. The ratio of firefly:Renilla luciferase activity increased significantly in hypoxic HCC-1954 cells (Fig. 1G). Mutation of 5'-CGT3' to 5'-AAA-3' in the HIF-1 binding site of the WWTRI HRE (underscored in text above) significantly decreased hypoxia-induced luciferase activity (compare MUT to WT in Fig. 1G). Taken together, the data in Fig. 1 and Fig. S1 demonstrate that HIF-1 binds directly to the WWTRI gene and activates its transcription in hypoxic breast cancer cells, leading to increased TAZ mRNA and protein expression.

\section{Expression of TAZ target genes in breast cancer cells is induced by hypoxia}

CTGF, PAI-1, and Survivin mRNA levels under nonhypoxic conditions were highest in the metastatic breast cancer lines (Fig. 2A), which was similar to the pattern of TAZ mRNA expression (Fig. 1A). In response to hypoxia, CTGF mRNA expression increased in MCF-7 and MDA-MB-435 cells, PAI-1 mRNA expression increased in MCF-10A, MCF-7 and HCC-1954 cells, whereas Survivin mRNA expression increased in all five breast cell lines (Fig. 2A). Hypoxic induction of CTGF, PAI-1, and survivin mRNA expression was selectively lost when expression of HIF-1 $\alpha$ (but not HIF-2 $\alpha$ ) was abrogated by shRNA (Fig. 2B). In contrast, in MDA-MB-231 subclones stably transduced with expression vector encoding either of two independent shRNAs targeting TAZ (shT1 and shT2), knockdown of TAZ expression decreased CTGF, PAI-1, and Survivin mRNA expression at both $20 \%$ and $1 \% \mathrm{O}_{2}$ (Fig. 2C). Immunoblot assays confirmed effective knockdown of TAZ protein expression, which did not affect HIF-1 $\alpha$ or HIF-2 $\alpha$ protein levels (Fig. 2D). ChIP assays revealed that hypoxia increased binding of TAZ to the $C T G F$ promoter, which was dependent on the expression of HIF- $1 \alpha$ and HIF-1ß (Fig. 2E). These data suggest that HIF-1 indirectly regulates TAZ target genes by increasing TAZ expression.

\section{Hypoxia induces HIF-1 $\alpha$-dependent TAZ nuclear localization}

Transcriptional regulation of TAZ by HIF-1 is surprising because most studies to date have focused on the regulation of TAZ subcellular localization by LATS1 and LATS2, which inhibit the nuclear localization of TAZ [7]. To determine whether hypoxia affects the subcellular localization of TAZ, MDA-MB-231 subclones were incubated at $20 \%$ or $1 \% \mathrm{O}_{2}$ for $48 \mathrm{~h}$ and stained with anti-TAZ antibody, Alexa 568-conjugated phalloidin (to detect F-actin in the cytoplasm), and DAPI (to stain nuclear DNA) (Fig. 3A). TAZ was localized primarily in the cytoplasm of non-hypoxic cells (Fig. 3B). In NTC and $\operatorname{sh} 2 \alpha$ cells, but not in sh $1 \alpha$ cells, exposure to hypoxia increased the expression of TAZ, which was localized primarily to nuclei (Fig. 3C), with decreased levels in the cytoplasm (Fig. 3B). We also prepared cytoplasmic and nuclear extracts, which were validated by immunoblot assays for $\alpha$-tubulin and histone $\mathrm{H} 3$, respectively, and confirmed that hypoxia induced TAZ nuclear localization in a HIF-1 $\alpha$-dependent and HIF-2 $\alpha$-independent manner (Fig. 3D).

\section{Hypoxia induces proteasomal degradation of LATS2 that is dependent on HIF-1 $\alpha$ and SIAH1}

We next analyzed the expression of LATS1 and LATS2, which negatively regulate TAZ nuclear localization [7]. Whereas LATS1 protein was constitutively expressed at low levels, LATS2 protein was highly expressed under non-hypoxic conditions and expression was dramatically decreased under hypoxic conditions in the four breast cancer cell lines that were analyzed (Fig. 4A). In contrast to LATS2 protein, LATS2 mRNA levels were not $\mathrm{O}_{2}$-regulated (Fig. 4B). The reduction in LATS2 protein levels in response to hypoxia was observed in NTC and sh $2 \alpha$ cells, but not in sh $1 \alpha$ cells (Fig. 4, C and D). Treatment of cells with the proteasome inhibitor MG132 blocked the degradation of HIF-1 $\alpha$ in non-hypoxic cells and LATS2 in hypoxic cells (Fig. 4E).

The proteasome-dependent degradation of LATS2 suggested that it might be subject to ubiquitination. SIAH1 and SIAH2 are E3 ubiquitin-protein ligases that are induced by hypoxia [33]. Analysis of gene expression data from human breast cancers revealed that SIAH1, but not SIAH2, mRNA expression showed a significant positive correlation with the expression of multiple 

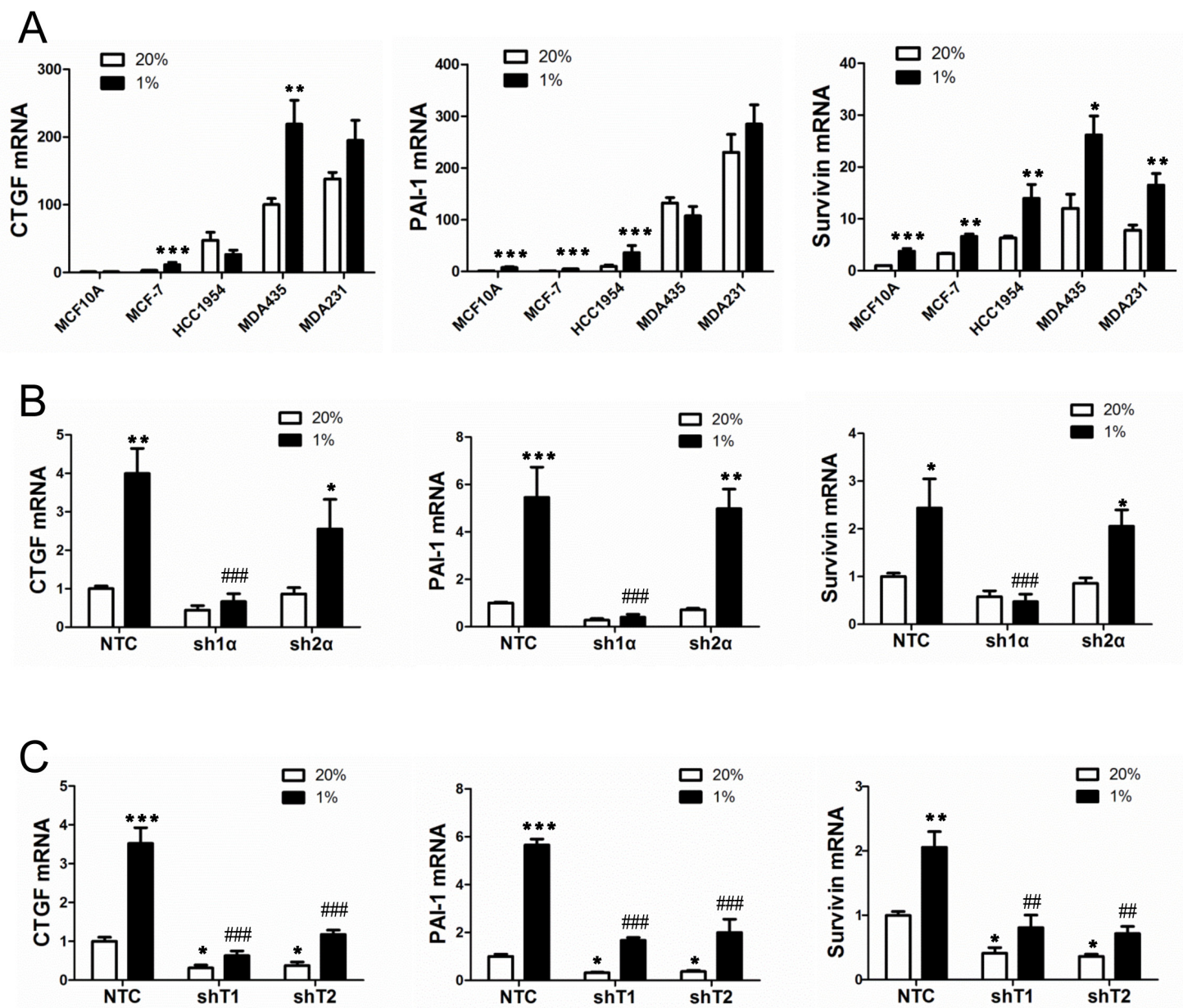

D

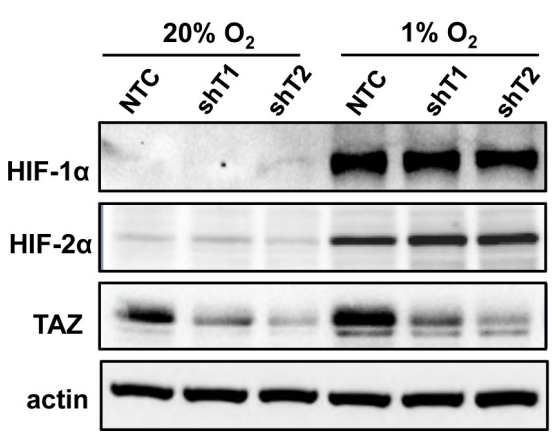

E

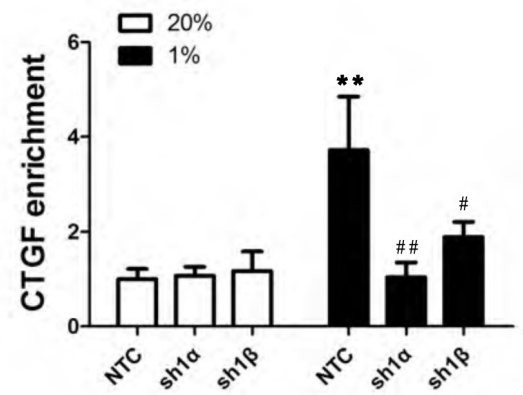

Figure 2: Analysis of TAZ target gene expression. (A) RT-qPCR was performed to quantify CTGF, PAI-1 and Survivin mRNA levels in breast cell lines following exposure to $20 \%$ or $1 \% \mathrm{O}_{2}$ for $24 \mathrm{~h}$. For each sample, the expression of CTGF, PAI-1 and Survivin mRNA was quantified relative to $18 \mathrm{~S}$ rRNA and normalized to lane 1 (mean $\pm \mathrm{SEM} ; \mathrm{n}=3$ ). ${ }^{*} P<0.05,{ }^{* *} P<0.01,{ }^{* * *} P<0.001$ versus $20 \%$ $\mathrm{O}_{2}$ (two-way ANOVA with Bonferroni post-test). (B-C) MCF-7 subclones expressing NTC, sh1 $\alpha$, sh2 $\alpha$ or either of two shRNAs targeting TAZ (shT1, shT2) were exposed to $20 \%$ or $1 \% \mathrm{O}_{2}$ for $24 \mathrm{~h}$ and expression of CTGF, PAI-1 and Survivin mRNA was analyzed by RT-qPCR. Data were normalized to lane 1 (mean \pm SEM; $\mathrm{n}=3$ ). ${ }^{*} P<0.05,{ }^{* *} P<0.01,{ }^{* * *} P<0.001$ versus NTC at $20 \% \mathrm{O}_{2}$; ${ }^{\# \#} P<0.01$, ${ }^{\# \#} P<0.001$ versus NTC at $1 \% \mathrm{O}_{2}$. (D) MDA-MB-231 subclones were exposed to $20 \%$ or $1 \% \mathrm{O}_{2}$ for $48 \mathrm{~h}$ and immunoblot assays were performed. (E) MCF-7 subclones were exposed to $20 \%$ or $1 \% \mathrm{O}_{2}$ for $16 \mathrm{~h}$. Chromatin was immunoprecipitated with anti-TAZ antibody and analyzed by qPCR with primers spanning the $C T G F$ promoter (mean $\pm \mathrm{SEM}, \mathrm{n}=3$ ). ${ }^{* *} P<0.01$ versus NTC at $20 \% \mathrm{O}_{2} ;{ }^{\#} P<0.05$, ${ }^{\# \#} P<0.01$ versus $\mathrm{NTC}$ at $1 \% \mathrm{O}_{2}$. 


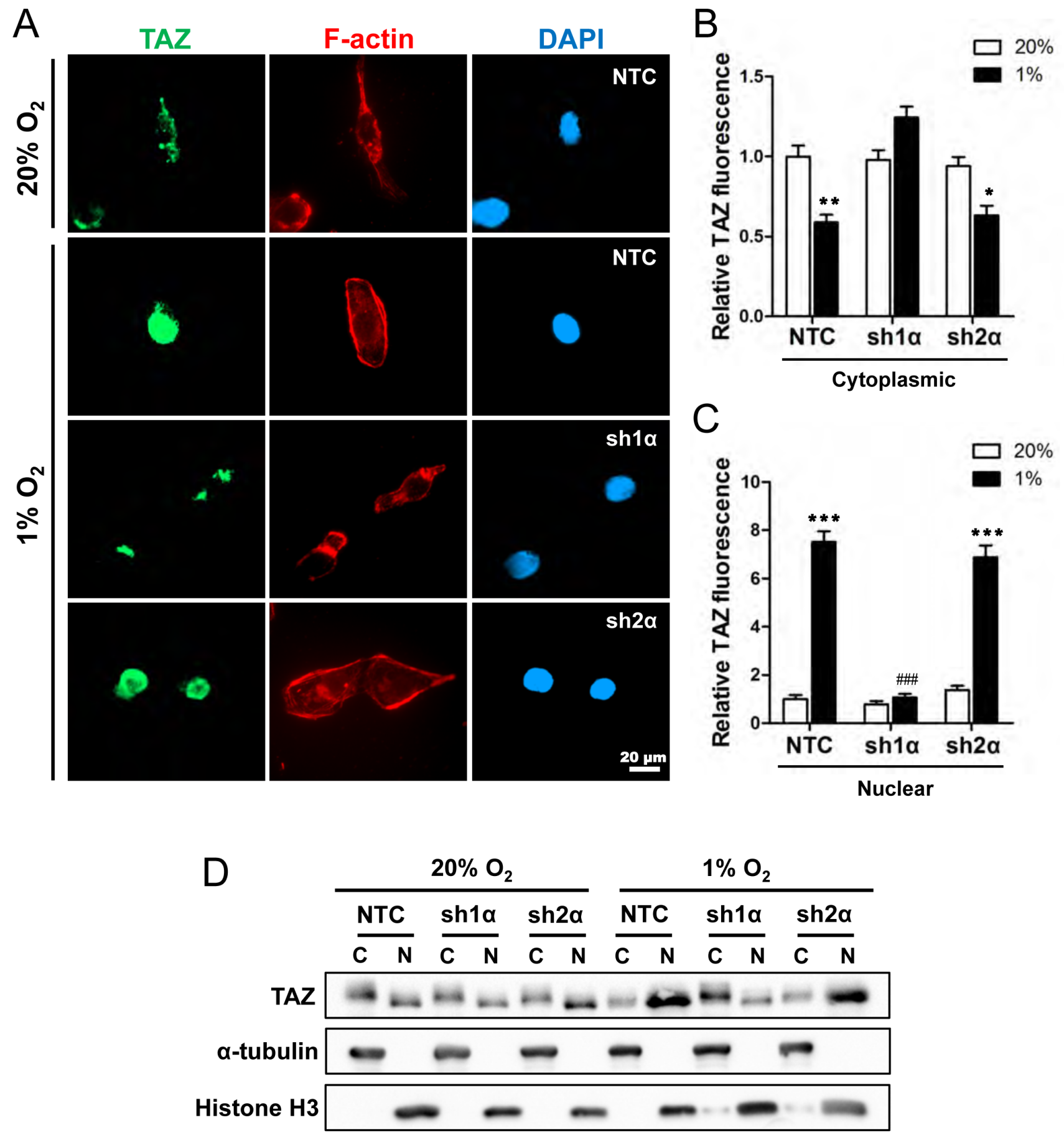

Figure 3: Analysis of TAZ subcellular localization. (A) MDA-MB-231 subclones (NTC, sh1 $\alpha$, and sh2 $\alpha$ ) were exposed to $20 \%$ or $1 \% \mathrm{O}_{2}$ for $48 \mathrm{~h}$ and stained with anti-TAZ antibody (green), Alexa Fluor 568-conjugated phalloidin to detect cytosolic F-actin (red), and DAPI to detect nuclear DNA (blue). (B-C) Image analysis was performed to determine the cytoplasmic (B) or nuclear (C) TAZ fluorescence intensity per cell normalized to lane 1 (mean $\pm \mathrm{SEM} ; \mathrm{n}=50$ cells). ${ }^{*} P<0.05,{ }^{* *} P<0.01,{ }^{* * *} P<0.001$ versus $\mathrm{NTC}$ at $20 \% \mathrm{O}_{2}$; ${ }^{\# \# \#} P<0.001$ versus NTC at $1 \% \mathrm{O}_{2}$ (two-way ANOVA with Bonferroni post-test). (D) Immunoblot assays of TAZ, histone $\mathrm{H} 3$, and $\alpha$-tubulin protein in cytosolic (C) and nuclear (N) lysates prepared from MDA-MB-231 subclones (NTC, sh1 $\alpha, \operatorname{sh} 2 \alpha$ ) exposed to $20 \%$ or $1 \%$ O for $48 \mathrm{~h}$. 

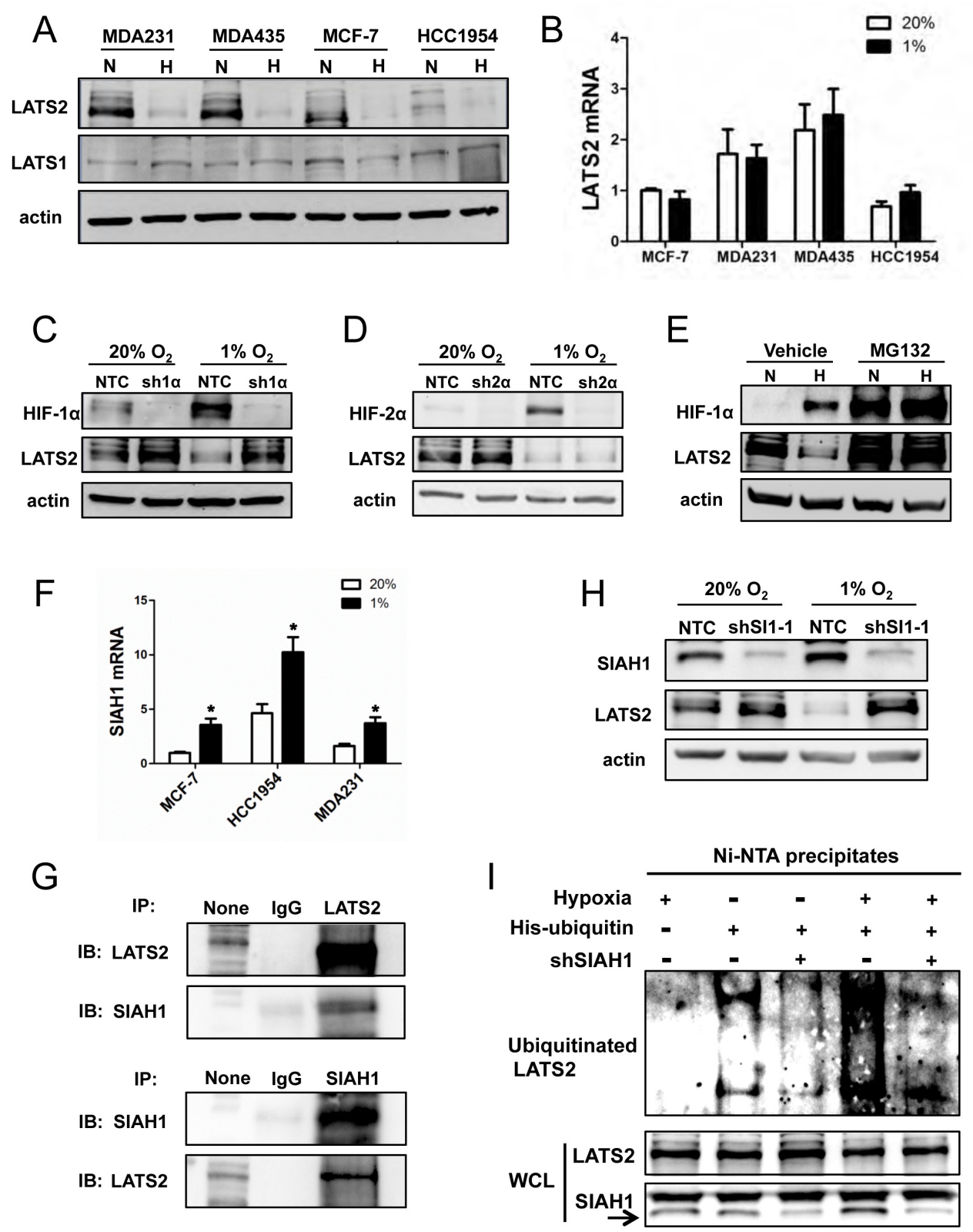

Figure 4: Analysis of LATS2 expression. (A) Immunoblot assays were performed to analyze actin, LATS1, and LATS2 protein levels in 4 breast cancer cell lines following exposure to $20 \%(\mathrm{~N})$ or $1 \%(\mathrm{H}) \mathrm{O}_{2}$ for $48 \mathrm{~h}$. (B) RT-qPCR was performed to quantify LATS2 mRNA levels in 4 breast cancer cell lines following exposure to $20 \%$ or $1 \% \mathrm{O}_{2}$ for $24 \mathrm{~h}$. For each sample, the expression of LATS $2 \mathrm{mRNA}$ was quantified relative to $18 \mathrm{~S}$ rRNA and then normalized to lane 1 (mean $\pm \mathrm{SEM} ; \mathrm{n}=3$ ). (C-D) Immunoblot assays were performed using antibodies against HIF-1 $\alpha$ (C), HIF-2 $\alpha$ (D), LATS2, and actin with whole cell lysates (WCLs) prepared from MDA-MB-231 subclones $\operatorname{sh} 1 \alpha(C), \operatorname{sh} 2 \alpha$ (D) and NTC (C and D), which were exposed to $20 \%$ or $1 \% \mathrm{O}_{2}$ for $48 \mathrm{~h}$. (E) MDA-MB-231 cells were exposed to $20 \% \mathrm{O}_{2}$ $(\mathrm{N})$ or $1 \% \mathrm{O}_{2}(\mathrm{H})$ for $48 \mathrm{~h}$, with $10 \mu \mathrm{M}$ MG132 or vehicle added for the last $6 \mathrm{~h}$, and immunoblot assays were performed using antibodies against HIF-1 $\alpha$, LATS2, and actin. (F) RT-qPCR was performed to determine SIAH1 mRNA levels in breast cell lines following exposure to $20 \%$ or $1 \% \mathrm{O}_{2}$ for $24 \mathrm{~h}$. For each sample, the expression of SIAH1 mRNA was quantified relative to $18 \mathrm{~S}$ rRNA and then normalized to the result obtained from MCF-7 cells at $20 \% \mathrm{O}_{2}$ (mean $\pm \mathrm{SEM} ; \mathrm{n}=3$ ). ${ }^{*} \mathrm{P}<0.05$ versus $20 \% \mathrm{O}_{2}$ (Student's $t$ test). (G) Immunoprecipitation (IP) was performed using IgG, anti-LATS2 (upper panels) or anti-SIAH1 (lower panel) antibody and WCL from MDA-MB-231 cells exposed to $1 \% \mathrm{O}_{2}$ for $48 \mathrm{~h}$ with $10 \mu \mathrm{M} \mathrm{MG} 132$ added for the last $6 \mathrm{~h}$. Immunoblot (IB) assays were performed with antibodies against LATS2 or SIAH1. None indicates aliquot of WCL prior to IP. (H) MDA-MB-231 cells were stably transduced with lentiviral vectors encoding NTC or shSIAH1 (shSI1) and exposed to $20 \%$ or $1 \% \mathrm{O}_{2}$ for $48 \mathrm{~h}$. Immunoblot assays were performed with antibodies against SIAH1, LATS2, and actin. (I) MDA-MB-231 cells were co-transfected with vectors encoding His-tagged ubiquitin and SIAH1 shRNA (shSIAH1 ${ }^{+}$) or nontargeting control shRNA (shSIAH1 $1^{-}$) and exposed to $1 \% \mathrm{O}_{2}$ for $48 \mathrm{~h}$ with $10 \mu \mathrm{M}$ MG132 added for the last $6 \mathrm{~h}$. Total ubiquitinated proteins were precipitated from WCLs by Ni-NTA beads and subject to immunoblot assay with anti-LATS2 antibodies (upper panel). Aliquots of WCL reserved prior to immunoprecipitation were assayed with antibodies against LATS2 and SIAH1 (lower panels). 
HIF target genes (Fig. S2A). The expression of mRNA encoding SIAH1, but not SIAH2, was also increased under hypoxic conditions in breast cancer cell lines (Fig. 4F and S2B). Next, MDA-MB-231 cells were exposed to $1 \%$ $\mathrm{O}_{2}$ for $48 \mathrm{~h}$ with MG132 treatment for the last $6 \mathrm{~h}$. Coimmunoprecipitation assays revealed physical interaction of LATS2 and SIAH1 (Fig. 4G). Knockdown of SIAH1 expression in MDA-MB-231 cells (shSI1-1 subclone) blocked the hypoxia-induced degradation of LATS2 (Fig. 4H). To analyze the effect of SIAH1 on LATS2 ubiquitination, MDA-MB-231 cells were co-transfected with vectors encoding His-tagged ubiquitin and shSI11 or NTC. The shSI1-1 vector, but not the NTC vector, markedly reduced levels of SIAH1 protein (Fig. 4I, bottom panel). Cells were exposed to hypoxia and treated with the proteasome inhibitor MG132 to block LATS2 degradation. The polyubiquitination of LATS2 was dramatically inhibited in SIAH1 knockdown cells as compared with NTC cells (Fig. 4I, top panel), whereas total LATS2 levels were similar (Fig. 4I, bottom panel).

\section{Hypoxia induces SIAH1 expression in a HIF-1- dependent manner}

Having found that SIAH1, but not SIAH2, mRNA increased under hypoxia in breast cancer cell lines, we next investigated whether SIAH1 gene expression is HIFregulated. Analysis of MDA-MB-231 subclones revealed that expression of SIAH1 mRNA (Fig. 5A) and protein (Fig. 5B) was induced by hypoxia in NTC and sh $2 \alpha$ cells but not in sh1 $\alpha$ cells. Analysis of the human SIAH1 gene revealed the sequence 5'-GCGTGAACGGCGTG-3', containing two potential HIF binding sites (in bold), on the sense strand within intron 1 , at a distance of 785 bp 3' to the transcription start site (Fig. $5 C$ ). To determine whether HIFs bind at this site, ChIP assays were performed in MCF-7 cells, which demonstrated hypoxia-inducible binding of HIF-1 $\alpha$ and HIF-1 $\beta$, but not HIF- $2 \alpha$, at this site (Fig. 5D). Similar results were obtained using HCC-1954 cells (Fig. S2, C-E). To test whether this putative HRE was functional, a 55-bp oligonucleotide spanning the site (Fig. 5C) was inserted into the reporter plasmid pGL2promoter. MCF-7 cells were co-transfected with pGL2/ SIAH1-HRE and pSV-Renilla and exposed to $20 \%$ or $1 \%$ $\mathrm{O}_{2}$ for $24 \mathrm{~h}$. The ratio of firefly:Renilla luciferase activity increased significantly in hypoxic MCF-7 cells (Fig. 5E). Mutation of the two HIF-1 binding sites (5'-CGT-3' to 5'AAA-3') in the SIAH1 HRE (underscored in text above) significantly decreased hypoxia-induced luciferase activity (compare MUT to WT in Fig. 5E).

\section{Nuclear localization of TAZ is dependent on SIAH1}

To determine whether hypoxia-induced SIAH1 expression affects the subcellular localization of TAZ, MDA-MB-231 subclones were incubated at $20 \%$ or $1 \%$ $\mathrm{O}_{2}$ for $48 \mathrm{~h}$ and stained with anti-TAZ antibody, as well as Alexa 568-conjugated phalloidin and DAPI (Fig. S3). TAZ was localized primarily in the cytoplasm of cells exposed to $20 \% \mathrm{O}_{2}$ whereas in NTC cells, but not in shSI1-1 cells, exposure to hypoxia increased the expression of TAZ, which was localized primarily to nuclei, with decreased levels in the cytoplasm (Fig. 5, F and G). Similar results were obtained by immunoblot assays of nuclear and cytoplasmic extracts from shSI1-1 or shSI1-2 cells (Fig. 5, H and I). Taken together, the data in Fig. 4 and Fig. 5 indicate that HIF-1 regulates the nuclear localization of TAZ by triggering the SIAH1-dependent proteasomal degradation of LATS2 in hypoxic breast cancer cells.

\section{HIF-1 $\alpha$, SIAH1, and TAZ regulate the breast cancer stem cell phenotype}

TAZ positively regulates BCSCs [10] and the enrichment of $\mathrm{ALDH}^{+} \mathrm{BCSCs}$ under hypoxic conditions is HIF-1 $\alpha$-dependent [3]. MDA-MB-231 cells were exposed to $20 \%$ or $1 \% \mathrm{O}_{2}$ for $72 \mathrm{~h}$ and the Aldefluor assay was performed followed by FACS to collect the $\mathrm{ALDH}^{+}$ population, which is highly enriched for BCSCs, and the ALDH' population, which is depleted of BCSCs. TAZ mRNA levels were significantly increased in $\mathrm{ALDH}^{+}$ as compared to $\mathrm{ALDH}^{-}$cells, and hypoxia induced TAZ expression in both cell populations (Fig. 6A). Analysis of MDA-MB-231 subclones revealed that hypoxia markedly increased the percentage of $\mathrm{ALDH}^{+} \mathrm{NTC}$ and sh $2 \alpha$ cells, whereas the hypoxic induction of BCSCs was abrogated in the sh $1 \alpha$ subclone; in contrast, $\mathrm{ALDH}^{+} \mathrm{BCSCs}$ were significantly decreased in the shT1 and shT2 subclones at both $20 \%$ and $1 \% \mathrm{O}_{2}$ (Fig. 6B).

To analyze whether HIF- $1 \alpha$ or TAZ is required for BCSC self-renewal, mammosphere formation assays were performed. MDA-MB-231 subclones were exposed to $20 \%$ or $1 \% \mathrm{O}_{2}$ for $72 \mathrm{~h}$ in adherent culture, then the cells were cultured on ultra-low attachment plates for $7 \mathrm{~d}$, and the resulting primary mammospheres were counted. Hypoxia increased primary mammosphere formation by NTC or sh $2 \alpha$ cells, but not by sh $1 \alpha$, cells (Fig. 6, C and D). The primary mammospheres were dissociated, replated on ultra-low attachment plates, and the number of secondary mammospheres was counted $7 \mathrm{~d}$ later. Secondary mammosphere formation was also markedly increased following exposure of NTC or $\operatorname{sh} 2 \alpha$ cells to hypoxia, whereas hypoxia-induced mammosphere formation was significantly impaired when $\operatorname{sh} 1 \alpha$, shT1, or shT2 cells were used; non-hypoxic cultures of these cells 
A

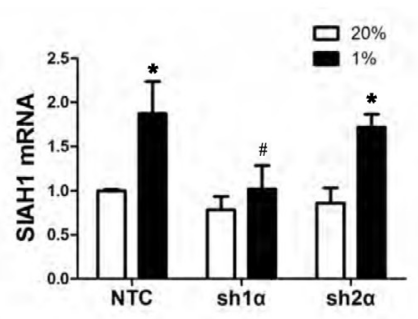

B

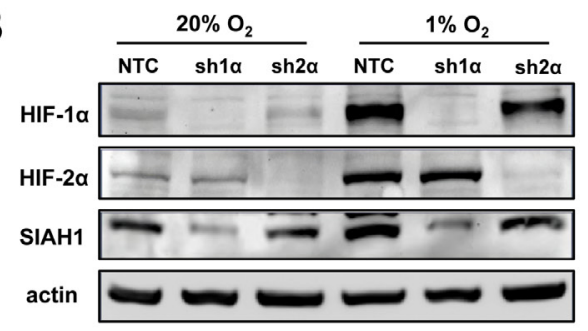

$\mathrm{E}$

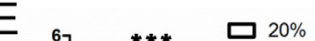

5'-ATGTCGITAGAGAGGAGAGCGCGTGAACGGCGTGCCGGGGAAGCTCTAGCTTATT-3'

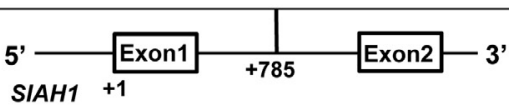

D
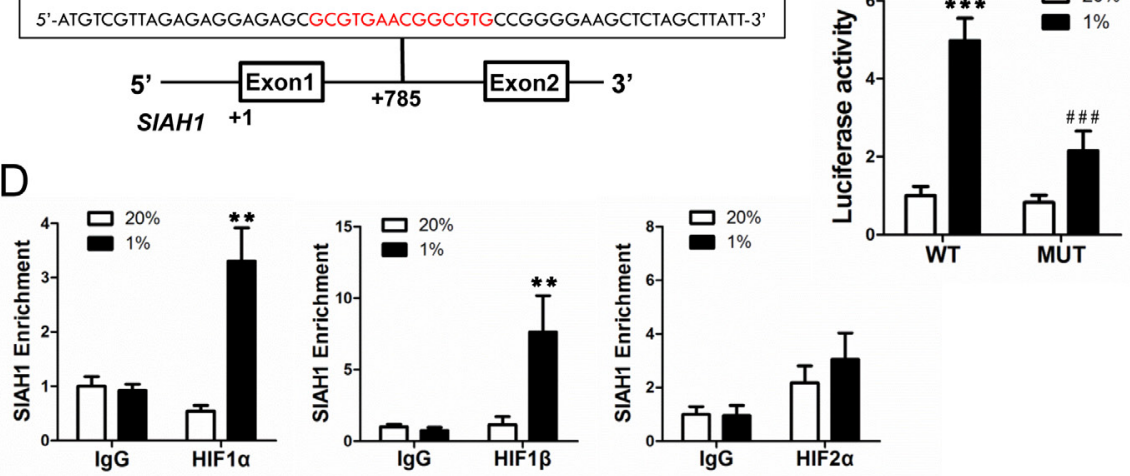

$\mathrm{F}$

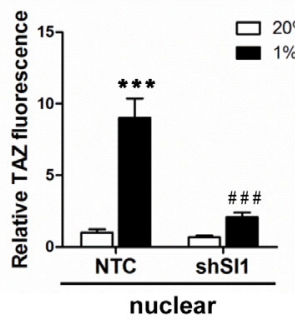

$\mathrm{G}$

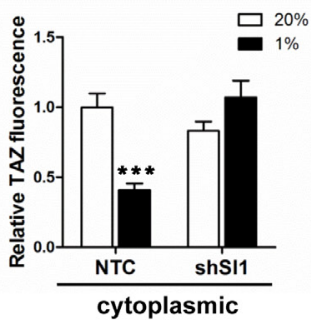

$\mathrm{H}$

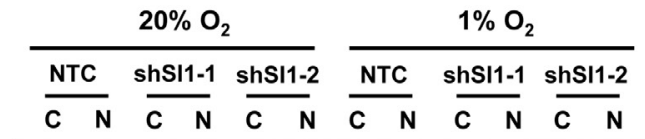

TAZ

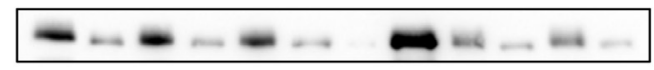

a-tubulin
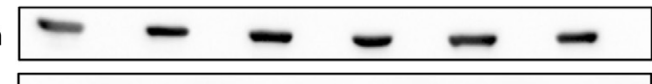

Histone $\mathrm{H} 3$
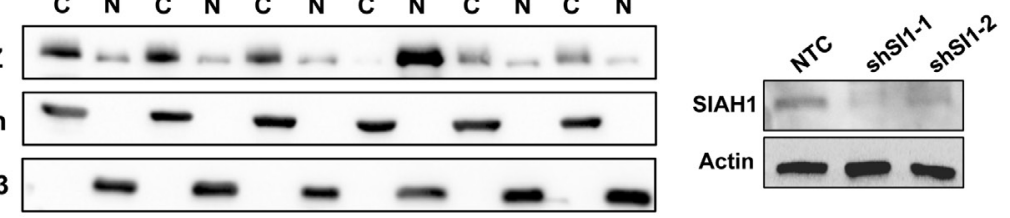

Figure 5: SIAH1 is a HIF-1 target gene product that regulates TAZ nuclear localization. (A) SIAH1 mRNA levels were analyzed by RT-qPCR in MDA-MB-231 subclones (NTC, sh1 $\alpha$, sh2 $\alpha$ ), which were exposed to $20 \%$ or $1 \% \mathrm{O}_{2}$ for $24 \mathrm{~h}$. The data were normalized to lane 1 (mean $\pm \mathrm{SEM} ; \mathrm{n}=3$ ). ${ }^{*} P<0.05$ versus $\mathrm{NTC}$ at $20 \% \mathrm{O}_{2},{ }^{;} P<0.05$ versus $\mathrm{NTC}$ at $1 \% \mathrm{O}_{2}$. (B) Immunoblot assays were performed using antibodies against HIF-1 $\alpha$, HIF-2 $\alpha$, SIAH1, and actin with WCLs prepared from MDA-MB-231 subclones (NTC, sh1 $\alpha$, sh $2 \alpha$ ) exposed to $20 \%$ or $1 \% \mathrm{O}_{2}$ for $48 \mathrm{~h}$. (C) The nucleotide sequence of a candidate HRE (two copies of HIF-1 binding site 5'-GCGTG-3' are shown in red) within intron 1 of the human SIAHI gene, located 785 bp 3' to the transcription start site, is shown. Exons and intron are not drawn to scale. (D) MCF-7 cells were exposed to $20 \%$ or $1 \% \mathrm{O}_{2}$ for $16 \mathrm{~h}$ and ChIP assays were performed using IgG or antibodies against HIF-1 $\alpha$, HIF- $2 \alpha$ or HIF-1 $\beta$. Primers flanking the HRE were used for qPCR and results were normalized to lane 1 (mean $\pm \mathrm{SEM} ; \mathrm{n}=3$ ). ${ }^{* *} P$ $<0.01$ versus $20 \% \mathrm{O}_{2}$ (Student's $t$ test). (E) The SIAHI HRE containing wild type (WT: 5'-GCGTGAACGGCGTG-3') or mutant (MUT; 5'-GAAAGAACGGAAAG-3') HIF-1 binding sites was inserted into pGL2-Promoter (encoding firefly luciferase) and co-transfected with pSV-Renilla (encoding Renilla luciferase) into MCF-7 cells, which were incubated at $20 \%$ or $1 \% \mathrm{O}_{2}$ for $24 \mathrm{~h}$. The firefly:Renilla luciferase

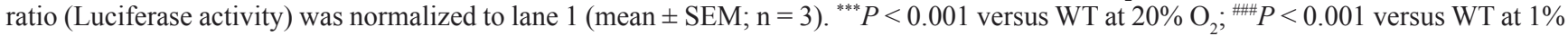
$\mathrm{O}_{2}$ (Student's $t$ test). (F-G) NTC or shSI-1 subclones were exposed to $20 \%$ or $1 \% \mathrm{O}_{2}$, subjected to immunofluorescent assays, and image analysis was performed to determine the nuclear (F) or cytoplasmic (G) TAZ fluorescence intensity per cell normalized to lane 1 (mean \pm SEM; $\mathrm{n}=50$ cells). ${ }^{* * *} P<0.001$ versus NTC at $20 \% \mathrm{O}_{2} ;{ }^{* \#+*} P<0.001$ versus NTC at $1 \% \mathrm{O}_{2}$ (two-way ANOVA with Bonferroni post-test). $(\mathrm{H})$ Left panel: Immunoblot assays of TAZ, histone $\mathrm{H} 3$, and $\alpha$-tubulin protein were performed using cytosolic $(\mathrm{C})$ and nuclear $(\mathrm{N})$ lysates prepared from MDA-MB-231 subclones (NTC, shSI1-1, shSI1-2) that were exposed to $20 \%$ or $1 \% \mathrm{O}_{2}$ for $48 \mathrm{~h}$. Right panel: Immunoblot assays were performed using antibodies against SIAH1 and actin with WCLs prepared from MDA-MB-231 NTC and SIAH1 knockdown subclones. 
A
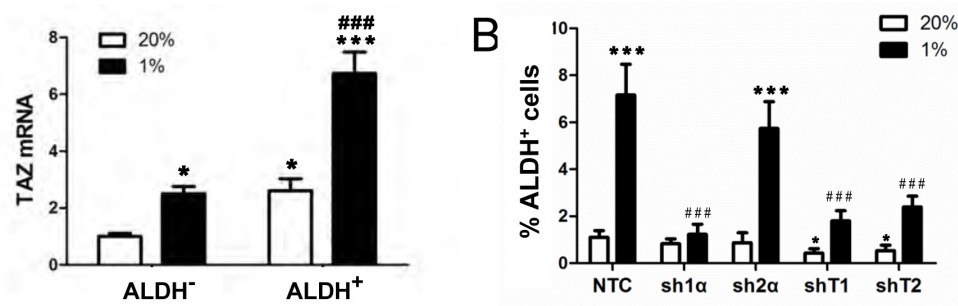

C

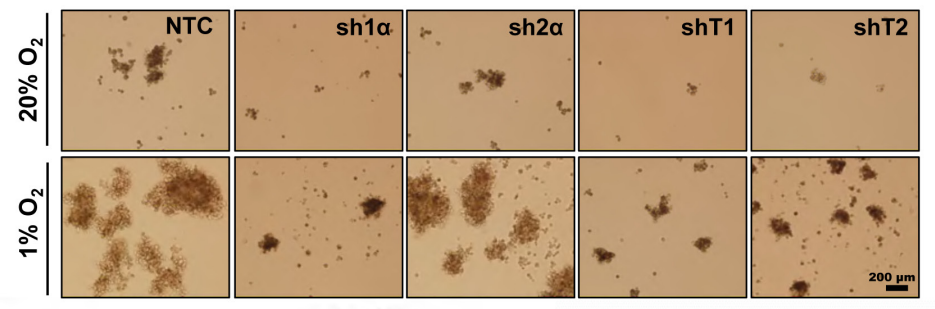

D
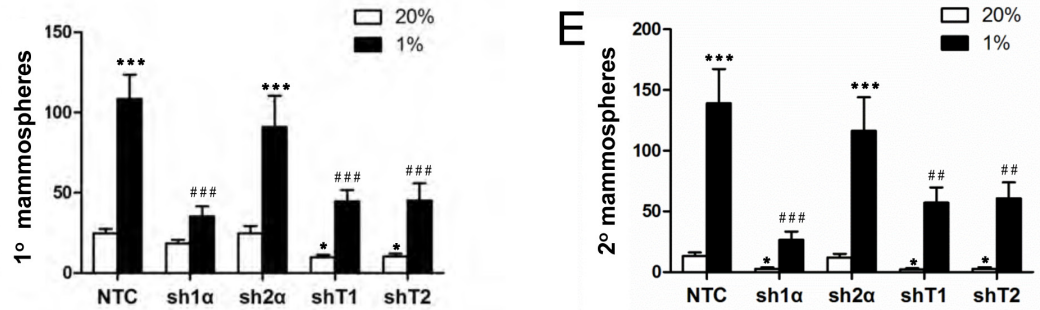

$\mathrm{F}$

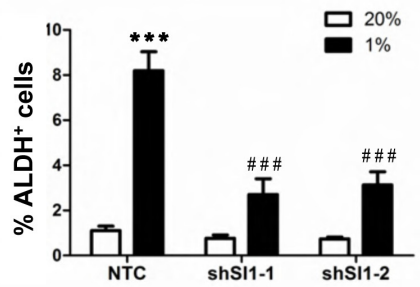

$\mathrm{H}$

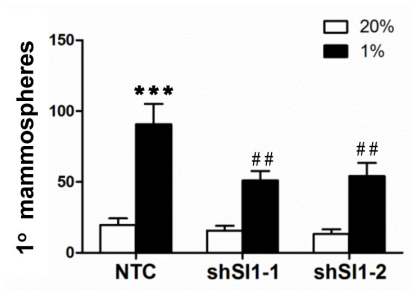

G
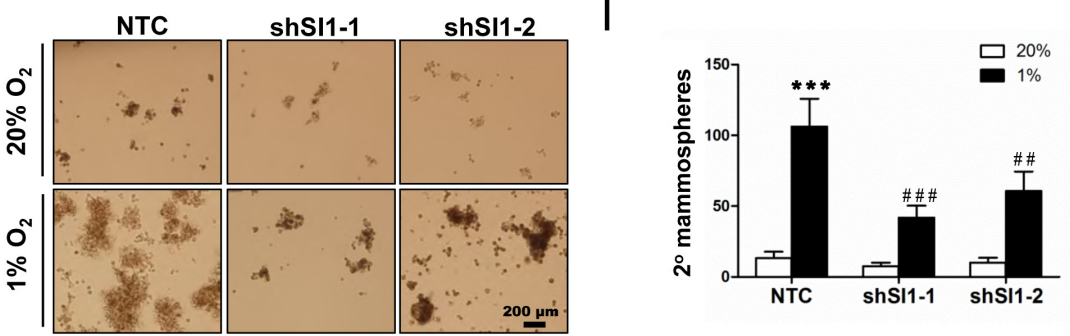

Figure 6: HIF-1 $\alpha$, TAZ, and SIAH1 regulate the breast cancer stem cell phenotype. (A) MDA-MB-231 cells were exposed to $20 \%$ or $1 \% \mathrm{O}_{2}$ for $72 \mathrm{~h}$, cells were sorted into aldehyde dehydrogenase ${ }^{+}\left(\mathrm{ALDH}^{+}\right)$and $\mathrm{ALDH}^{-}$populations by FACS, and TAZ mRNA expression was determined by RT-qPCR and normalized to lane 1 (mean $\pm \mathrm{SEM} ; \mathrm{n}=6$ ). ${ }^{*} P<0.05$ versus $\mathrm{ALDH}^{-}$at $20 \% \mathrm{O}_{2}$; ${ }^{* * *} P<0.001$ versus $\mathrm{ALDH}^{+}$at $20 \% \mathrm{O}_{2} ;{ }^{\prime \prime} P<0.001$ versus $\mathrm{ALDH}^{-}$at $1 \% \mathrm{O}_{2}$. (B) MDA-MB-231 subclones (NTC, sh1 $\alpha, \operatorname{sh} 2 \alpha$, shT1, shT2) were exposed to $20 \%$ or $1 \% \mathrm{O}_{2}$ for $72 \mathrm{~h}$ and the percentage of $\mathrm{ALDH}^{+}$cells was determined by flow cytometry (mean $\pm \mathrm{SEM} ; \mathrm{n}=3$ ). ${ }^{*} P<0.05,{ }^{* * *} P<$ 0.001 versus NTC at $20 \% \mathrm{O}_{2} ;{ }^{\prime \prime} P<0.001$ versus NTC at $1 \% \mathrm{O}_{2}$. (C-E) MDA-MB-231 subclones were exposed to $20 \%$ or $1 \%$ O for $72 \mathrm{~h}$. Cells were seeded at a density of 5,000 cells $/ \mathrm{mL}$, cultured for $7 \mathrm{~d}(\mathrm{C})$, and the number of primary mammospheres $\geq 70 \mu \mathrm{m}$ in diameter was counted. The mammospheres were dissociated and seeded at a density of 2,000 cells $/ \mathrm{mL}$, cultured for $7 \mathrm{~d}$, and secondary mammospheres were counted. The number of primary (D) and secondary (E) mammospheres per 1000 cells initially seeded was calculated (mean $\pm \mathrm{SEM}$; $\mathrm{n}=3$ ). ${ }^{*} P<0.05,{ }^{* * *} P<0.001$ versus NTC at $20 \% \mathrm{O}_{2}$; ${ }^{\#} P<0.01,{ }^{\#} P<0.001$ versus NTC at $1 \% \mathrm{O}_{2}$. (F) MDA-MB-231 subclones (NTC, shSI1-1, shSI1-2) were exposed to $20 \%$ or $1 \% \mathrm{O}$ for $72 \mathrm{~h}$ and the percentage of ALDH ${ }^{+}$cells was determined by Aldefluor assay and flow

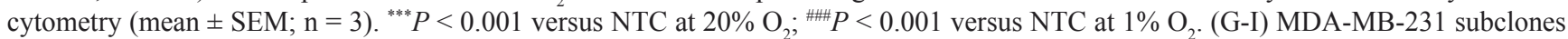
(NTC, shSI1-1, shSI1-2) were exposed to $20 \%$ or $1 \% \mathrm{O}_{2}$ for $72 \mathrm{~h}$. Cells were seeded at a density of 5,000 cells $/ \mathrm{mL}$, cultured for $7 \mathrm{~d}(\mathrm{G})$ and the number of primary mammospheres $\geq 70 \mu \mathrm{m}$ in diameter was counted. The mammospheres were enzymatically dissociated, and the resulting single cells were seeded at a density of 2,000 cells $/ \mathrm{mL}$, cultured for $7 \mathrm{~d}$, and secondary mammospheres were counted. The number of primary $(\mathrm{H})$ and secondary (I) mammospheres per 1000 cells initially seeded was calculated (mean $\pm \mathrm{SEM} ; \mathrm{n}=3$ ). ${ }^{* * *} P<0.001$ versus NTC at $20 \% \mathrm{O}_{2},{ }^{\# \# P} P<0.01,{ }^{\# \#} P<0.001$ versus NTC at $1 \% \mathrm{O}_{2}$. 
also showed impaired secondary mammosphere formation compared to NTC or sh $2 \alpha$ cells (Fig. 6E).

If hypoxic induction of the BCSC phenotype is due in part to SIAH1-dependent degradation of LATS2, then SIAH1 knockdown should also reduce the BCSC population. Analysis of MDA-MB-231 subclones revealed that hypoxia markedly increased the percentage of $\mathrm{ALDH}^{+}$ NTC cells, whereas the hypoxic induction of BCSCs was significantly decreased in two independent SIAH1 knockdown (shSI1-1 and shSI1-2) subclones (Fig. 6F). Hypoxia increased primary mammosphere formation when NTC cells were used, but not when SIAH1 knockdown subclones were used (Fig. 6, G and H). Hypoxia-induced secondary mammosphere formation was also significantly impaired when SIAH1 knockdown subclones were used (Fig. 6I).

\section{LATS2 knockdown induces breast cancer stem cell phenotype and TAZ nuclear localization}

To investigate whether LATS2 loss of function was sufficient to induce the BCSC phenotype, we generated two independent LATS2 knockdown subclones of MDAMB-231 (Fig. 7A). LATS2 knockdown increased the percentage of $\mathrm{ALDH}^{+}$cells (Fig. 7B) as well as primary and secondary mammosphere formation (Fig. 7, C and D). LATS2 knockdown also increased the nuclear localization of TAZ at $20 \% \mathrm{O}_{2}$ (Fig. 7E). We next investigated whether SIAH1 or LATS2 knockdown affected TAZ transcriptional activity. A 247-bp $C T G F$ gene promoter fragment, which contains three copies of the TAZ/TEAD-binding site sequence (5'-GGAATG-3') and no match to the HIF-1 binding site consensus sequence (5'-RCGTG-3'), was inserted into pGL2-Basic (pGL2-CTGF). MCF-7 cells were co-transfected with the following plasmids: pGL2CTGF or pGL2; pSV-Renilla; and an expression vector encoding a non-targeting control shRNA (NTC) or either of two independent shRNAs targeting SIAH1 or LATS2. The ratio of pGL2-CTGF:pSV-Renilla activity was increased in response to hypoxia in NTC cells, whereas knockdown of SIAH1 significantly impaired the induction of luciferase activity under hypoxic conditions. Knockdown of LATS2 increased luciferase activity under non-hypoxic conditions (Fig. 7F). Thus, TAZ transcriptional activity is repressed by LATS 2 under non-hypoxic conditions and de-repressed under hypoxic conditions in a SIAH1-dependent manner.

\section{HIF and TAZ activity affect tumor formation and patient mortality}

To investigate whether HIFs and TAZ regulate the tumor-initiating potential of breast cancer cells in vivo, we injected 1000 NTC, $\operatorname{sh} 1 \alpha, \operatorname{sh} 2 \alpha$, or shT1 cells into the mammary fat pad of female SCID mice. Whereas NTC cells formed tumors in the all of the injected mice by $71 \mathrm{~d}$ after injection, HIF-1 $\alpha$ knockdown cells showed a complete loss of tumor-initiating ability and knockdown of TAZ or HIF- $2 \alpha$ impaired, but did not eliminate, tumor formation (Fig. 8A). In contrast, both HIF [21] and TAZ [10] knockdown subclones have previously been shown to initiate tumors as efficiently as control MDA-MB-231 subclones when $>10^{4}$ cells were injected. Taken together, these results are consistent with the hypothesis that tumor initiation is dependent on HIF and TAZ activity.

To determine the clinical relevance of HIF- $1 \alpha$ and TAZ expression in breast cancer, survival data were analyzed by stratifying patients according to the expression of HIF- and TAZ-regulated genes in the primary tumor. Kaplan-Meier plots revealed that breast cancers with high expression (above the median) of both HIF and TAZ target genes were associated with significantly decreased patient survival over 10 years as compared to cancers with low expression of one or both signatures (Fig. 8B).

\section{DISCUSSION}

The median $\mathrm{PO}_{2}$ in advanced breast cancers is 10 $\mathrm{mmHg}\left(\sim 1.5 \% \mathrm{O}_{2}\right)$, as compared to $65 \mathrm{mmHg}$ in normal breast tissue, and those cancers below the median $\mathrm{PO}_{2}$ are at increased risk of metastasis and mortality [34]. Intratumoral hypoxia induces the expression of HIF-1 $\alpha$, which is associated with increased risk of metastasis, relapse, and mortality in multiple clinical studies involving thousands of breast cancer patients [35-44]. Only BCSCs possess the ability to form metastatic and recurrent tumors [45]. The observation that hypoxia increased the $\mathrm{ALDH}^{+}$ population in a HIF-1 $\alpha$-dependent manner [3] provided a link between increased HIF- $1 \alpha$ levels and BCSCs, but the mechanism by which HIF- $1 \alpha$ stimulates the BCSC phenotype was not delineated.

In this study, we have demonstrated that HIF1 stimulates both the expression and activity of TAZ, a transcriptional co-activator that is required for maintenance of BCSCs [10]. HIF- $1 \alpha$ binds to an HRE in the WWTR 1 gene and activates its transcription, leading to increased TAZ mRNA and protein expression; in addition, HIF- $1 \alpha$ binds to an HRE in the SIAH1 gene and activates its transcription, leading to LATS2 ubiquitination and degradation, which increases TAZ nuclear localization (Fig. 8C). While this work was in progress, HIF- $1 \alpha$ and TAZ interaction in breast cancer bone metastases was reported and shown to stimulate HIF-1 transcriptional activity [46], suggesting reciprocal positive interactions between HIF-1 and TAZ. However, it is the HIF-1mediated increase in the expression, nuclear localization, and transcriptional activity of TAZ that provides a novel molecular mechanism by which intratumoral hypoxia induces the BCSC phenotype. The demonstration that HIF-1 mediates increased expression of TAZ and its positive regulator SIAH1 is conceptually similar to our 
A

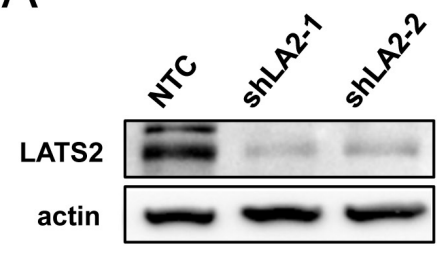

C

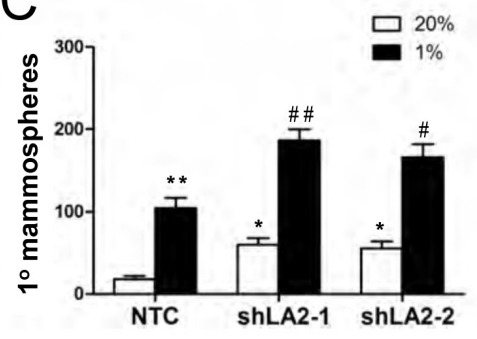

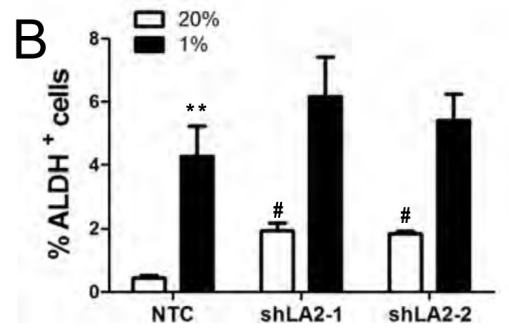

D

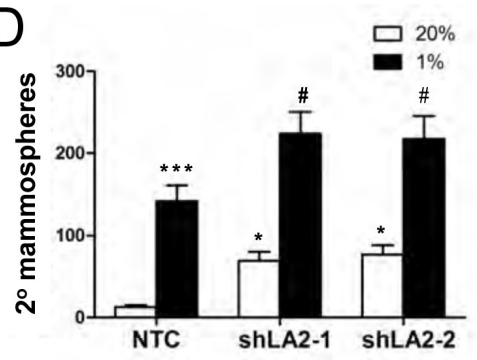

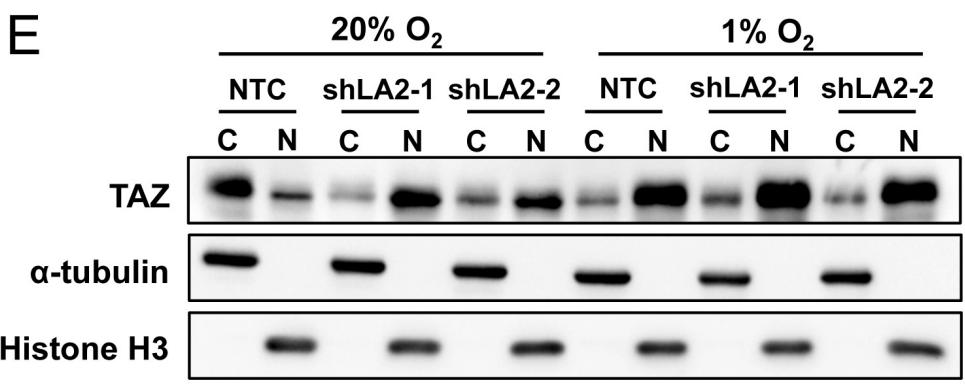

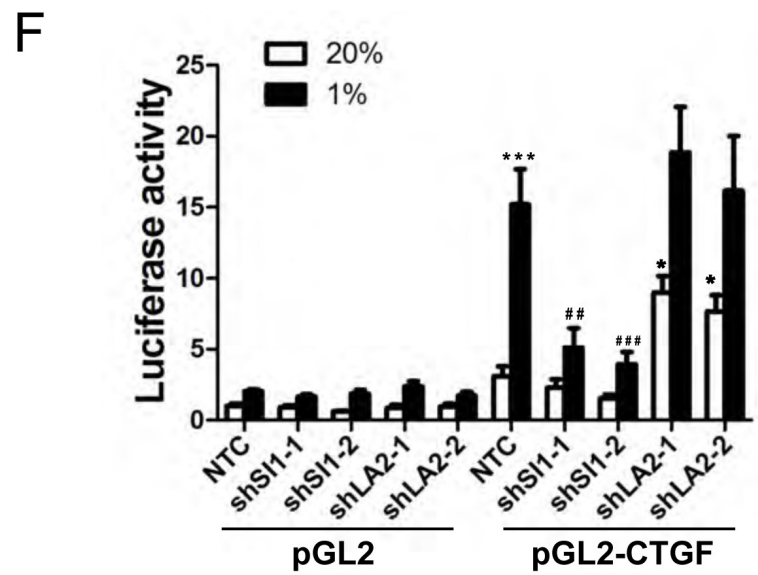

Figure 7: LATS2 knockdown induces breast cancer stem cell phenotype and TAZ nuclear localization. (A) Immunoblot assays were performed using antibodies against LATS2 and actin with cell extracts prepared from MDA-MB-231 subclones (NTC, shLA21, shLA2-2). (B) MDA-MB-231 subclones (NTC, shLA2-1, shLA2-2) were exposed to $20 \%$ or $1 \% \mathrm{O}_{2}$ for $72 \mathrm{~h}$ and the percentage of $\mathrm{ALDH}^{+}$cells was determined by Aldefluor assay and flow cytometry (mean $\pm \mathrm{SEM} ; \mathrm{n}=3$ ). ${ }^{* *} P<0.01$ versus NTC at $20 \% \mathrm{O}_{2} ;{ }^{*} P<0.05$ versus NTC at $1 \% \mathrm{O}_{2}$. (C-D) MDA-MB-231 subclones (NTC, shLA2-1, shLA2-2) were exposed to $20 \%$ or $1 \% \mathrm{O}_{2}$ for $72 \mathrm{~h}$. The number of primary (C) and secondary (D) mammospheres per 1000 cells initially seeded was determined (mean $\pm \mathrm{SEM} ; \mathrm{n}=4$ ). ${ }^{*} P<0.05,{ }^{* *} P<0.01$, ${ }^{* * *} P<0.001$ versus NTC at $20 \% \mathrm{O}_{2} ;{ }^{\#} P<0.05,{ }^{\# \#} P<0.01$ versus NTC at $1 \% \mathrm{O}_{2}$. (E) Immunoblot assays of TAZ, histone $\mathrm{H} 3$, and $\alpha$-tubulin protein were performed using cytosolic $(\mathrm{C})$ and nuclear $(\mathrm{N})$ lysates prepared from MDA-MB-231 subclones (NTC, shLA2-1, shLA2-2) that were exposed to $20 \%$ or $1 \% \mathrm{O}_{2}$ for $48 \mathrm{~h}$. (F) MCF-7 cells were transfected with pGL2 or pGL2-CTGF, pSV-Renilla, and an expression vector encoding a non-targeting control shRNA (NTC) or two independent shRNAs targeting LATS2 or SIAH1, and exposed to $20 \%$ or $1 \%$ $\mathrm{O} 2$ for $24 \mathrm{~h}$. The luciferase activity was normalized to lane 1 (mean $\pm \mathrm{SEM}, \mathrm{n}=4$ ). ${ }^{*} P<0.05,{ }^{* * *} P<0.001$ versus $\mathrm{NTC}$ at $20 \% \mathrm{O}_{2}$; ${ }^{\# \#} P<$ 0.01 , \#\# $P<0.001$ versus NTC at $1 \% \mathrm{O}_{2}$. 
finding that HIFs mediate the expression of Rho Kinase 1 and its positive regulator Rho A to stimulate the motility of hypoxic breast cancer cells [19].

HIF-1 $\alpha$, but not HIF-2 $\alpha$, was required for the hypoxia-induced expression of TAZ and SIAH1, which was consistent with the finding that HIF-1 $\alpha$, but not HIF-2 $\alpha$, was required for hypoxic induction of the BCSC phenotype as measured by the Aldefluor and mammosphere formation assays. However, HIF- $2 \alpha-$ deficient cells showed reduced tumorigenicity, which suggests that HIF-2 $\alpha$ may be required for aspects of the $\mathrm{BCSC}$ phenotype that are not captured by the in vitro assays.

Analysis of the TCGA human breast cancer database revealed that the combination of increased HIF and TAZ target gene expression was associated with a significantly increased risk of patient mortality as compared to increased expression of either HIF or TAZ target genes. This finding is consistent with the established role of HIFs in regulating other key pathways involved in breast cancer metastasis. It also may reflect the involvement of other factors in the regulation of TAZ activity. In this regard, it should be noted that hypoxia induced HIF-1-dependent TAZ expression in all breast cancer cell lines, whereas under non-hypoxic conditions, TAZ levels were increased in metastatic breast cancer cells, relative to non-metastatic cells, through a HIF-independent mechanism.

The administration of anti-angiogenic agents

A

\begin{tabular}{|c|c|c|c|c|}
\hline \multicolumn{5}{|c|}{ Tumor initiation capacity } \\
\hline Injected subclone & NTC & sh1 $\alpha$ & sh2 $\alpha$ & shT1 \\
\hline Tumor formation & $7 / 7$ & $\begin{array}{c}0 / 7 \\
(P<0.001)\end{array}$ & $\begin{array}{c}2 / 7 \\
(P<0.05)\end{array}$ & $\begin{array}{c}3 / 7 \\
(\text { n.s. })\end{array}$ \\
\hline
\end{tabular}

B

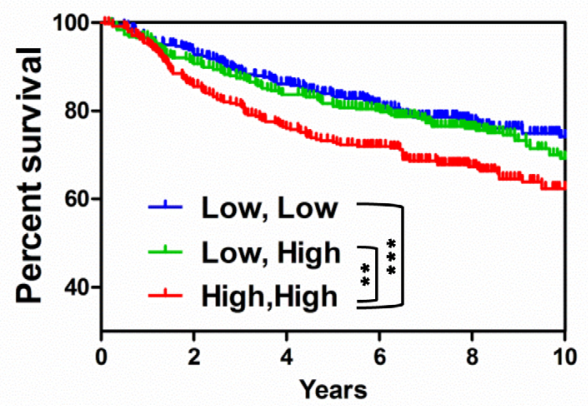

C

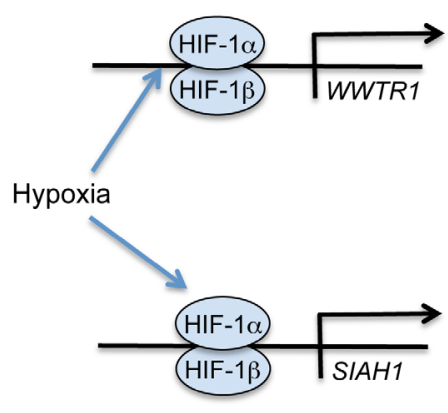

Transactivation of
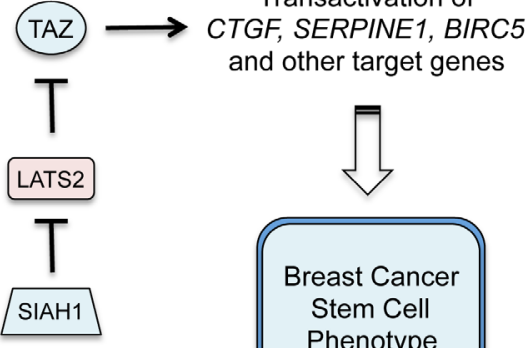
and other target genes

Figure 8: Effect of HIF and TAZ activity on tumorigenicity and patient survival. (A) To analyze the tumor-initiating capacity of the NTC, sh $1 \alpha, \operatorname{sh} 2 \alpha$, and shT1 subclones, 1000 cells were injected into the mammary fat pad of immunodeficient female mice. The table reports the number of mice developing palpable tumors after $71 \mathrm{~d}$. The Chi-square test was performed to determine statistical significance versus NTC; n.s., not significant. (B) Kaplan-Meier analysis of disease-specific survival for 1,098 breast cancer patients stratified by TAZ and HIF signatures in the primary tumor. High, High (red): patients with both TAZ and HIF signatures greater than the median $(\mathrm{N}=356)$. Low, High (green): patients with TAZ or HIF signature greater than the median and the other signature less than the median $(\mathrm{N}=382)$. Low, Low (blue): patients with both signatures less than the median $(\mathrm{N}=360)$. The Wilcoxon rank sum test was used to compare survival curves $(* * P<0.01, * * * P<0.001)$. (C) HIF-1 activates transcription of the WWTR1 and SIAH1 genes to stimulate TAZ expression and nuclear localization, respectively, and induce the breast cancer stem cell phenotype in response to hypoxia. 
to tumor-bearing mice has been shown to increase intratumoral hypoxia and thereby increase the percentage of BCSCs [3]. Our data implicate HIF-1-dependent induction of TAZ transcriptional activity in hypoxiainduced BCSC enrichment and suggest that coadministration of a HIF-1 inhibitor may be necessary to block the counter-therapeutic effects of anti-angiogenic agents.

The basal-like molecular subclass of human breast cancers is characterized by increased expression of HIF target genes and largely overlaps with the triple-negative clinical subclass of breast cancers that lack expression of the estrogen receptor, progesterone receptor, and HER2 [31]. These cancers are currently treated with cytotoxic chemotherapy that results in a durable response in less than $20 \%$ of patients. In orthotopic mouse models of triple negative breast cancer, drugs that block HIF$1 \alpha$ accumulation inhibit primary tumor growth and vascularization, local tissue invasion, regional lymph node metastasis, and lung metastasis, as well as reducing the percentage of BCSCs in the primary tumor [20, 21, 47], suggesting that co-administration of a HIF-1 inhibitor with chemotherapy may improve outcome in this patient population.

\section{METHODS}

\section{Statistical analysis of microarray data}

Gene expression data from the Breast Invasive Carcinoma dataset (TCGA) were obtained from https:// genome-cancer.ucsc.edu. Pearson's correlation coefficient was used to determine $P$ values for co-expression.

\section{Cell culture}

Breast cell lines MCF-10A, MDA-MB-231, MDA-MB-435 and MCF-7 were cultured as previously described [19]. HCC1954 cells were cultured in RPMI1640 supplemented with $10 \%$ fetal bovine serum and $1 \%$ penicillin-streptomycin. All cells were maintained at $37^{\circ} \mathrm{C}$ in a $5 \% \mathrm{CO}_{2} / 95 \%$ air incubator. For hypoxic exposure, cells were placed in a modular incubator chamber (Billups-Rothenberg) and flushed with a $1 \%$ $\mathrm{O}_{2} / 5 \% \mathrm{CO}_{2} / 94 \% \mathrm{~N}_{2}$ gas mixture. MG132 was purchased from Calbiochem.

\section{ShRNA, lentiviruses, and transduction}

Vectors encoding shRNA targeting HIF-1 $\alpha(\operatorname{sh} 1 \alpha 1)$ and HIF-2 $\alpha$ were previously described [21]. The shRNA vectors encoding NTC and sh $1 \alpha 2$ were purchased from Sigma. pLKO.1-puro lentiviral vectors encoding shRNA targeting TAZ and SIAH1 were purchased from SigmaAldrich: shT1 (Clone ID: NM_015472.3-706s1c1); shT2 (Clone ID: NM_015472.3-1657s21c1); shSI1-1 (Clone ID: NM_003031.3-563s21c1); shSI1-2 (Clone ID: NM 00303 $1.3-826 \mathrm{~s} 21 \mathrm{c} 1$ ); shLA2-1 (Clone ID: NM 014572.x-3750s1c1) and shLA2-2 (Clone ID: NM_014572.x-2162s1c1). Lentiviral vectors were cotransfected with plasmid pCMV-dR8.91 and a plasmid encoding vesicular stomatitis virus $G$ protein into 293T cells using Lipofectamine 2000 (Invitrogen). Medium containing viral particles was collected $48 \mathrm{~h}$ after transfection and passed through a $0.45-\mu \mathrm{M}$ filter. MDA-MB-231, MDA-MB-435 and MCF-7 cells were transduced with viral supernatant supplemented with $8 \mu \mathrm{g} /$ $\mathrm{mL}$ of Polybrene (Sigma-Aldrich). After $24 \mathrm{~h}$, cells were selected in medium containing $0.6 \mu \mathrm{g} / \mathrm{mL}$ of puromycin (Sigma-Aldrich).

\section{Luciferase reporter plasmid constructs and assays}

To construct the WWTR1-HRE and SIAH1-HRE reporters, 55-bp double-stranded oligonucleotides were inserted between the BamHI and SalI sites of pGL2-Promoter (Promega). All plasmid constructs were confirmed by nucleotide sequence analysis. A 247-bp CTGF promoter sequence was amplified from human genomic DNA by PCR (primers: 5'-CCCCTCGAGAGTGTGCCAGCTTTTTCAGAC-3' and 5'-CGAAGCTTCGAGCTGGAGGGTGGAGT-3'), purified by gel extraction, and inserted into the XhoI and HindIII sites of pGL2-Basic (Promega). For HRE reporter assays [48], cells were seeded onto 48-well plates and cotransfected with recombinant pGL2-Promoter plasmid, which contained HRE-WT or HRE-MUT sequences, and pSV-Renilla. Transfected cells were exposed to $20 \%$ or $1 \% \mathrm{O}_{2}$ for $24 \mathrm{~h}$. Firefly luciferase and Renilla luciferase activities in cell lysates were determined using the DualLuciferase Assay System (Promega).

\section{RT-qPCR}

Total cellular RNA was extracted using TRIzol (Invitrogen), precipitated with isopropanol, treated with DNase I (Ambion), and reverse transcribed with the iScript cDNA Synthesis kit (Bio-Rad). qPCR analysis was performed using SYBR Green and the iCycler Real-time PCR Detection System (BioRad). The $2^{-\Delta \Delta C t}$ method was used to calculate the relative gene expression [21]. Primer sequences are listed in Table S1.

\section{Subcellular fractionation}

MDA-MB-231 subclones were resuspended in hypotonic buffer [10 mM HEPES/KOH (pH 7.5), $1 \mathrm{mM}$ 
$\mathrm{K}_{2}$ EDTA, $10 \mathrm{mM} \mathrm{KCl}, 1.5 \mathrm{mM} \mathrm{MgCl}, 1 \mathrm{mM}$ EGTA, $0.1 \%$ Igepal, $1 \mathrm{mM}$ DTT, and protease inhibitor cocktail (Roche)], incubated on ice for $30 \mathrm{~min}$, and disrupted in a Dounce homogenizer (60 strokes). The nuclei were collected by centrifugation at $800 \mathrm{~g}$ for $10 \mathrm{~min}$, washed twice with isotonic buffer (hypotonic buffer plus $250 \mathrm{mM}$ sucrose) and lysed in isotonic buffer by sonication. The supernatant was reserved as the cytosolic fraction.

\section{Immunoprecipitation and immunoblot assays}

Whole cell lysates (WCLs) were prepared in RIPA lysis buffer. For co-immunoprecipitation assays, 30 $\mu \mathrm{l}$ of protein G-Sepharose beads (GE Healthcare) and immunoprecipitating antibody were incubated with 0.75 $\mathrm{mg}$ of WCL overnight at $4^{\circ} \mathrm{C}$. Beads were washed 5 times in lysis buffer. Proteins were eluted in SDS sample buffer and separated by SDS-PAGE. Antibodies used in immunoblot and co-immunoprecipitation assays were: HIF-1 $\alpha$ (BD Transduction Laboratory); HIF-2 $\alpha$, TAZ, LATS2, LATS1, SIAH1, histone H3, $\alpha$-tubulin, IgG (Novus Biologicals); and $\beta$-actin (Santa Cruz). HRPconjugated anti-rabbit (Amersham) and anti-mouse (Santa Cruz) secondary antibodies were used. Chemiluminescent signal was developed using ECL Plus (GE Healthcare). For ubiquitination assays, cells were co-transfected with vector encoding His-tagged ubiquitin, and shSI1 or NTC vector, and exposed to $1 \% \mathrm{O}_{2}$ for $48 \mathrm{~h}$ with $10 \mu \mathrm{M} \mathrm{MG132}$ added for the last $6 \mathrm{~h}$. Total ubiquitinated proteins were precipitated from WCLs by Ni-NTA beads (Qiagen) and subjected to immunoblot assays.

\section{ChIP assay}

ChIP assays were performed as previously described [18]. HCC1954 and MCF-7 cells were cross-linked in $3.7 \%$ formaldehyde for $10 \mathrm{~min}$ and lysed with SDS lysis buffer. Chromatin was sheared by sonication and lysates were pre-cleared with salmon sperm DNA/protein A-agarose slurry (Millipore) and incubated with $\operatorname{IgG}$ (Novus Biologicals) or antibodies against the following proteins: HIF-1 $\alpha$ (Santa Cruz), HIF- $2 \alpha$, HIF- $1 \beta$ and TAZ (Novus Biologicals). Salmon sperm DNA/protein A-agarose slurry was added and the agarose beads were washed sequentially with: low- and high-salt immune complex wash buffers; LiCl immune complex wash buffer; and twice with TE buffer (10 mM Tris-HCl/1 mM EDTA). DNA was eluted in $1 \%$ SDS with $0.1 \mathrm{M} \mathrm{NaHCO}_{3}$, and crosslinks were reversed by addition of $0.2 \mathrm{M} \mathrm{NaCl}$. DNA was purified by phenol-chloroform extraction and ethanol precipitation, suspended in $50 \mu \mathrm{TE}$ buffer, and $2-\mu l$ aliquots were used for qPCR. Primer sequences are listed in Table S1.

\section{Immunohistochemistry}

Tumors were fixed in $10 \%$ formalin and paraffin embedded. Sections were dewaxed in xylene, hydrated with graded ethanol, followed by antigen retrieval using citrate buffer ( $\mathrm{pH}$ 6.1). The LSAB + System HRP kit (DAKO) was used with antibodies against TAZ and P4HA1 (Novus Biologicals). Sections were counterstained with Mayer's hematoxylin (Sigma). HIF$1 \alpha$ immunohistochemistry was performed as described [49].

\section{Immunofluorescence}

MDA-MB-231 cells plated on Lab-Tek II chamber slides (Thermo Fisher Scientific) were fixed with $4 \%$ paraformaldehyde (Sigma), permeabilized with $0.1 \%$ Triton X-100 (Fisher) for 5 min, blocked with PBS supplemented with $10 \%$ BSA for $20 \mathrm{~min}$, and stained with anti-TAZ antibody (Novus Biologicals) overnight at $4^{\circ} \mathrm{C}$, followed by incubation with FITC-conjugated goat anti-rabbit IgG (Novus Biologicals). F-actin and nuclear DNA were stained using Alexa Fluor 568-conjugated phalloidin (Life Technologies) and $300 \mathrm{nM}$ DAPI (Invitrogen), respectively. Fluorescent imaging was performed using a $63 \times(1.4 \mathrm{NA})$, oil immersion objective on an AxioObserver microscope (Carl Zeiss), which was equipped with ApoTome. 2 and an ORCA-ERG digital camera (Hamamatsu). Images were processed with ZEN software 2012 (Carl Zeiss). Fluorescence intensities of TAZ in nucleus and cytoplasm were determined using ImageJ software (NIH). Fifty cells were randomly imaged and scored for each experiment, and data from three independent experiments were plotted as mean + SEM.

\section{Aldefluor assay and flow cytometry}

Cells were exposed to $20 \%$ or $1 \% \mathrm{O}_{2}$ for $72 \mathrm{~h}$ and subject to Aldefluor assay (Stem Cell Technologies). Cells were suspended in assay buffer containing 1 $\mu \mathrm{mol} / \mathrm{L}$ BODIPY-aminoacetaldehyde and incubated for $40 \mathrm{~min}$ at $37^{\circ} \mathrm{C}$. As a negative control, for each sample an aliquot of cells was treated with the ALDH inhibitor diethylaminobenzaldehyde $(50 \mathrm{mM})$. Samples were subjected to flow cytometry analysis (FACScalibur, BD Biosciences). The top and bottom 5\% of Aldefluor expressing cells were sorted by FACS and considered $\mathrm{ALDH}^{+}$and $\mathrm{ALDH}$, respectively, for RNA analysis.

\section{Mammosphere assays}

Cells were exposed to $20 \%$ or $1 \% \mathrm{O}_{2}$ in monolayer adherent culture for $72 \mathrm{~h}$. Single cells were counted and plated on 6-well ultra-low attachment culture plates 
(Corning) at a density of 5000 cells/mL for primary mammosphere formation and 2000 cells $/ \mathrm{mL}$ for secondary mammosphere formation in complete Mammocult medium (Stem Cell Technologies). Mammospheres (diameter $\geq 70 \mu \mathrm{m}$ ) were counted after $7 \mathrm{~d}$. Mammosphere cultures were imaged using an Olympus phase-contrast microscope and mammosphere diameters were determined using ImageJ software. Mammospheres were collected by centrifugation at $800 \mathrm{rpm}$ and enzymatically dissociated by incubation in trypsin-EDTA solution (Invitrogen) for $2 \mathrm{~min}$ at $37^{\circ} \mathrm{C}$. Single cell suspensions were then counted and reseeded for secondary mammosphere formation.

\section{Orthotopic transplantation}

Studies using 6- to 8-week-old female SCID mice (NCI) were performed according to protocols approved by the Johns Hopkins University Animal Care and Use Committee in accordance with the NIH Guide for the Care and Use of Laboratory Animals. $1 \times 10^{3}$ cells of MDAMB-231 subclones were suspended in $100 \mu \mathrm{l}$ Matrigel (BD Biosciences) and injected into the mammary fat pad. Tumor formation was assayed by palpation.

\section{Survival analysis}

Seven Affymetrix HG-U133A microarray datasets, which together totaled 1,098 breast cancer patient samples annotated with histological tumor grade and survival outcome, were downloaded from the NCBI Gene Expression Omnibus (http://www.ncbi.nlm.nih. gov/geo/): GSE1456 [50]; GSE3494 [51]; GSE4922 [52]; GSE6532 [53-55]; GSE2990 [56]; GSE7390 [57]; and GSE11121 [58]. The TAZ/YAP pathway signature has been previously reported as genes with expression induced $>2$-fold in both TAZ-overexpressing and YAPoverexpressing MCF10A cells [8]. The HIF signature consists of 10 genes with mRNA expression induced by hypoxia in MDA-MB-231 cells in a HIF-dependent manner: P4HA1, P4HA2, PLOD1, PLOD2, VEGFA, LOX, $L 1 C A M, S L C 2 A 1, C X C R 3, P D G F B$. The mean expression for all genes in the signature was determined and patients were stratified by low ( $<$ median) versus high $(>$ median) signature expression.

\section{Statistical analysis}

Data are presented as mean \pm SEM and were analyzed using an unpaired two-tailed Student's t-test for two groups or ANOVA followed by Bonferroni posttest for multiple groups. The Chi-square test was used for analyzing tumor formation. Survival data were analyzed using Kaplan Meier survival plots and $p$ values were calculated using the Wilcoxon rank sum test. $P$ values $<$
0.05 were considered significant.

\section{ACKNOWLEDGMENTS}

The authors are grateful to Karen Padgett of Novus Biologicals for generously providing FITCconjugated goat anti-rabbit IgG and antibodies against $\alpha$-tubulin, HIF-1 $\beta$, HIF-2 $\alpha$, Histone H3, LATS1, LATS2, SIAH1, and TAZ. L.X., D.M.G., N.T., and W.L. were supported by the China Scholarship Council, National Cancer Institute (K99-CA181352), Japan Science and Technology Agency, and National Cancer Institute (K99CA168746), respectively. G.L.S. is an American Cancer Society Research Professor and the C. Michael Armstrong Professor at the Johns Hopkins University School of Medicine.

\section{REFERENCES}

1. Ginestier C, Hur MH, Charafe-Jauffret E, Monville F, Dutcher J, Brown M, Jacquemier J, Viens P, Kleer CG, Liu S, Schott A, Hayes D, Birnbaum D, et al. ALDH1 is a marker of normal and malignant human mammary stem cells and a predictor of poor clinical outcome. Cell Stem Cell 2007;1(5):555-567.

2. Charafe-Jauffret E, Ginestier C, Iovino F, Wicinski J, Cervera N, Finetti P, Hur MH, Diebel ME, Monville F, Dutcher J, Brown M, Viens P, Xerri L, et al. Breast cancer cell lines contain functional cancer stem cells with metastatic capacity and a distinct molecular signature. Cancer Res 2009;69(4):1302-1313.

3. Conley SJ, Gheordunescu E, Kakarala P, Newman B, Korkaya H, Heath AN, Clouthier SG and Wicha MS. Antiangiogenic agents increase breast cancer stem cells via the generation of tumor hypoxia. Proc Natl Acad Sci U S A 2012;109(8):2784-2789.

4. Dontu G, Abdallah WM, Foley JM, Jackson KW, Clarke MF, Kawamura MJ, and Wicha MS. In vitro propagation and transcriptional profiling of human mammary stem/ progenitor cells. Genes Dev 2003;17(10):1253-1270.

5. Ponti D, Costa A, Zaffaroni N, Pratesi G, Petrangolini G, Coradini D, Pilotti S, Pierotti MA and Daidone MG. Isolation and in vitro propagation of tumorigenic breast cancer cells with stem/progenitor cell properties. Cancer Res 2005;65(13):5506-5511.

6. Kao J, Salari K, Bocanegra M, Choi YL, Girard L, Gandhi J, Kwei KA, Hernandez-Boussard T, Wang P, Gazdar AF, Minna JD and Pollack JR. Molecular profiling of breast cancer cell lines defines relevant tumor models and provides a resource for cancer gene discovery. PloS One 2009;4(7):e6146.

7. Pan D. The hippo signaling pathway in development and cancer. Dev Cell 2010;19(4):491-505.

8. Zhang H, Liu CY, Zha ZY, Zhao B, Yao J, Zhao S, Xiong Y, Lei QY and Guan KL. TEAD transcription factors 
mediate the function of TAZ in cell growth and epithelialmesenchymal transition. J Biol Chem 2009;284(20):1335513362.

9. Lai D, Ho KC, Hao Y, and Yang X. Taxol resistance in breast cancer cells is mediated by the hippo pathway component TAZ and its downstream transcriptional targets Cyr61 and CTGF. Cancer Res 2011;71(7):2728-2738.

10. Cordenonsi M, Zanconato F, Azzolin L, Forcato M, Rosato A, Frasson C, Inui M, Montagner M, Parenti AR, Poletti A, Daidone MG, Dupont S, Basso G, et al. The Hippo transducer TAZ confers cancer stem cell-related traits on breast cancer cells. Cell 2011;147(4):759-772.

11. Pobbati AV and Hong W. Emerging roles of TEAD transcription factors and its coactivators in cancers. Cancer Biol Ther 2013;14(5):390-398.

12. Li Z, Bao S, Wu Q, Wang H, Eyler C, Sathornsumetee S, Shi Q, Cao Y, Lathia J, McLendon RE, Hjelmeland AB and Rich JN. Hypoxia-inducible factors regulate tumorigenic capacity of glioma stem cells. Cancer Cell 2009;15(6):501513.

13. Schwab LP, Peacock DL, Majumdar D, Ingels JF, Jensen LC, Smith KD, Cushing RC and Seagroves TN. Hypoxiainducible factor 1a promotes primary tumor growth and tumor-initiating cell activity in breast cancer. Breast Cancer Res 2012;14(1):R6.

14. Wang Y, Liu Y, Malek SN, Zheng P and Liu Y. Targeting HIF-1a eliminates cancer stem cells in hematological malignancies. Cell Stem Cell 2011;8(4):399-411.

15. Takubo K, Goda N, Yamada W, Iriuchishima H, Ikeda E, Kubota Y, Shima H, Johnson RS, Hirao A, Suematsu M and Suda T. Regulation of the HIF-1a level is essential for hematopoietic stem cells. Cell Stem Cell 2010;7(3):391402.

16. Mathieu J, Zhou W, Xing Y, Sperber H, Ferreccio A, Agoston Z, Kuppusamy KT, Moon RT and Ruohola-Baker H. Hypoxia-inducible factors have distinct and stagespecific roles during reprogramming of human cells to pluripotency. Cell Stem Cell 2014;14(5):592-605.

17. Semenza GL. Hypoxia-inducible factors in physiology and medicine. Cell 2012;148(3):399-408.

18. Chaturvedi P, Gilkes DM, Wong CC, Kshitiz, Luo W, Zhang H, Wei H, Takano N, Schito L, Levchenko A and Semenza GL. Hypoxia-inducible factor-dependent breast cancer-mesenchymal stem cell bidirectional signaling promotes metastasis. J Clin Invest 2013;123(1):189-205.

19. Gilkes DM, Xiang L, Lee SJ, Chaturvedi P, Hubbi ME, Wirtz D and Semenza GL. Hypoxia-inducible factors mediate coordinated RhoA-ROCK1 expression and signaling in breast cancer cells. Proc Natl Acad Sci U S A 2014;111(3):E384-E393.

20. Schito L, Rey S, Tafani M, Zhang H, Wong CC, Russo A, Russo MA and Semenza GL. Hypoxia-inducible factor 1-dependent expression of platelet-derived growth factor $\mathrm{B}$ promotes lymphatic metastasis of hypoxic breast cancer cells. Proc Natl Acad Sci U S A 2012;109(40):E2707-E2716.

21. Zhang H, Wong CC, Wei H, Gilkes DM, Korangath P, Chaturvedi P, Schito L, Chen J, Krishnamachary B, Winnard PT Jr, Raman V, Zhen L, Mitzner WA, et al. HIF1-dependent expression of angiopoietin-like 4 and L1CAM mediates vascular metastasis of hypoxic breast cancer cells to the lungs. Oncogene 2012;31(14):1757-1770.

22. Erler JT, Bennewith KL, Nicolau M, Dornhöfer N, Kong C, Le QT, Chi JT, Jeffrey SS and Giaccia AJ. Lysyl oxidase is essential for hypoxia-induced metastasis. Nature 2006;440(7088):1222-1226.

23. Hiraga T, Kizaka-Kondoh S, Hirota K, Hiraoka M and Yoneda T. Hypoxia and hypoxia-inducible factor-1 expression enhance osteolytic bone metastases of breast cancer. Cancer Res 2007;67(9):4157-4163.

24. Liao D, Corle C, Seagroves TN and Johnson RS. Hypoxiainducible factor-1a is a key regulator of metastasis in a transgenic model of cancer initiation and progression. Cancer Res 2007;67(2):563-572.

25. Dunn LK, Mohammad KS, Fournier PG, McKenna CR, Davis HW, Niewolna M, Peng XH, Chirgwin JM and Guise TA. Hypoxia and TGF-b drive breast cancer bone metastases through parallel signaling pathways in tumor cells and the bone microenvironment. PloS One 2009;4(9):e6896.

26. Semenza GL. Defining the role of hypoxia-inducible factor 1 in cancer biology and therapeutics. Oncogene 2010;29(5):625-634.

27. Gilkes DM and Semenza GL. Role of hypoxia-inducible factors in breast cancer metastasis. Future Oncol 2013;9(11):1623-1636.

28. Gilkes DM, Bajpai S, Wong CC, Chaturvedi P, Hubbi ME, Wirtz D and Semenza GL. Procollagen lysyl hydroxylase 2 is essential for hypoxia-induced breast cancer metastasis. Mol Cancer Res 2013;11(5):456-466.

29. Gilkes DM, Chaturvedi P, Bajpai S, Wong CC, Wei H, Pitcairn S, Hubbi ME, Wirtz D and Semenza GL. Collagen prolyl hydroxylases are essential for breast cancer metastasis. Cancer Res 2013;73(11):3285-3296.

30. Chaturvedi P, Gilkes DM, Takano N and Semenza GL. Hypoxia-inducible factor-dependent signaling between triple-negative breast cancer cells and mesenchymal stem cells promotes macrophage recruitment. Proc Natl Acad Sci U S A 2014;111(20):E2120-2129.

31. Cancer Genome Atlas Network. Comprehensive molecular portraits of human breast tumours. Nature 2012;490(7418):61-70.

32. Semenza GL. Hypoxia-inducible factor 1 and cardiovascular disease. Annu Rev Physiol 2014;76:39-56.

33. Nakayama K, Frew IJ, Hagensen M, Skals M, Habelhah H, Bhoumik A, Kadoya T, Erdjument-Bromage H, Tempst P, Frappell PB, Bowtell DD and Ronai Z. Siah2 regulates stability of prolyl-hydroxylases, controls HIF-1a abundance, 
and modulates physiological responses to hypoxia. Cell 2004;117(7):941-952.

34. Vaupel P, Mayer A and Hockel M. Tumor hypoxia and malignant progression. Methods Enzymol 2004;381:335354.

35. Schindl M, Schoppmann SF, Samonigg H, Hausmaninger H, Kwasny W, Gnant M, Jakesz R, Kubista E, Birner P, Oberhuber G and Austrian Breast and Colorectal Cancer Study Group. Overexpression of hypoxia-inducible factor 1a is associated with an unfavorable prognosis in lymph node-positive breast cancer. Clin Cancer Res 2002;8(6):1831-1837.

36. Bos R, van der Groep P, Greijer AE, Shvarts A, Meijer S, Pinedo HM, Semenza GL, van Diest PJ and van der Wall E. Levels of hypoxia-inducible factor-1a independently predict prognosis in patients with lymph node negative breast carcinoma. Cancer 2003;97(6):1573-1581.

37. Giatromanolaki A, Koukourakis MI, Simopoulos C, Polychronidis A, Gatter KC, Harris AL and Sivridis E. c-erbB-2 related aggressiveness in breast cancer is hypoxia inducible factor-1a dependent. Clin Cancer Res 2004;10(23):7972-7977.

38. Dales JP, Garcia S, Meunier-Carpentier S, Andrac-Meyer L, Haddad O, Lavaut MN, Allasia C, Bonnier P and Charpin C. Overexpression of hypoxia-inducible factor HIF-1a predicts early relapse in breast cancer: retrospective study in a series of 745 patients. Int J Cancer 2005;116(5):734739 .

39. Vleugel MM, Greijer AE, Shvarts A, van der Groep P, van Berkel M, Aarbodem Y, van Tinteren H, Harris AL, van Diest PJ and van der Wall E. Differential prognostic impact of hypoxia induced and diffuse HIF-1a expression in invasive breast cancer. J Clin Pathol 2005;58(2):172-177.

40. Generali D, Berruti A, Brizzi MP, Campo L, Bonardi S, Wigfield S, Bersiga A, Allevi G, Milani M, Aguggini S, Gandolfi V, Dogliotti L, Bottini A, et al. Hypoxiainducible factor-1a expression predicts a poor response to primary chemoendocrine therapy and disease-free survival in primary human breast cancer. Clin Cancer Res 2006;12(15):4562-4568.

41. Kronblad A, Jirstrom K, Ryden L, Nordenskjold B and Landberg G. Hypoxia inducible factor-1a is a prognostic marker in premenopausal patients with intermediate to highly differentiated breast cancer but not a predictive marker for tamoxifen response. Int $\mathrm{J}$ Cancer 2006;118(10):2609-2616.

42. Chen HH, Su WC, Lin PW, Guo HR and Lee WY. Hypoxiainducible factor-1a correlates with MET and metastasis in node-negative breast cancer. Breast Cancer Res Treat 2007;103(2):167-175.

43. Trastour C, Benizri E, Ettore F, Ramaioli A, Chamorey E, Pouysségur J and Berra E. HIF-1a and CA IX staining in invasive breast carcinomas: prognosis and treatment outcome. Int J Cancer 2007;120(7):1451-1458.
44. Yamamoto Y, Ibusuki M, Okumura Y, Kawasoe T, Kai $\mathrm{K}$, Iyama $\mathrm{K}$ and Iwase $\mathrm{H}$. Hypoxia-inducible factor $1 \mathrm{a}$ is closely linked to an aggressive phenotype in breast cancer. Breast Cancer Res Treat 2008;110(3):465-475.

45. Oskarsson T, Batlle E and Massague J. Metastatic stem cells: sources, niches, and vital pathways. Cell Stem Cell 2014;14(3):306-321.

46. Bendinelli P, Maroni P, Matteucci E, Luzzati A, Perrucchini $\mathrm{G}$ and Desiderio MA. Hypoxia inducible factor-1 is activated by transcriptional co-activator with PDZ-binding motif (TAZ) versus WW domain-containing oxidoreductase (WWOX) in hypoxic microenvironment of bone metastasis from breast cancer. Eur J Cancer 2013;49(11):2608-2618.

47. Xiang L, Gilkes DM, Chaturvedi P, Luo W, Hu H, Takano N, Liang H and Semenza GL. Ganetespib blocks HIF-1 activity and inhibits tumor growth, vascularization, stem cell maintenance, invasion, and metastasis in orthotopic mouse models of triple-negative breast cancer. J Mol Med (Berl) 2014;92(2):151-164.

48. Semenza GL, Jiang BH, Leung SW, Passantino R, Concordet JP, Maire $\mathrm{P}$ and Giallongo A. Hypoxia response elements in the aldolase $\mathrm{A}$, enolase 1 , and lactate dehydrogenase A gene promoters contain essential binding sites for hypoxia-inducible factor 1 . J Biol Chem 1996;271(51):32529-32537.

49. Krishnamachary B and Semenza GL. Analysis of hypoxiainducible factor 1a expression and its effects on invasion and metastasis. Methods Enzymol 2007;435:347-354.

50. Pawitan Y, Bjöhle J, Amler L, Borg AL, Egyhazi S, Hall P, Han X, Holmberg L, Huang F, Klaar S, Liu ET, Miller L, Nordgren H, et al. Gene expression profiling spares early breast cancer patients from adjuvant therapy: derived and validated in two population-based cohorts. Breast Cancer Res 2005;7(6):R953-964.

51. Miller LD, Smeds J, George J, Vega VB, Vergara L, Ploner A, Pawitan Y, Hall P, Klaar S, Liu ET and Bergh J. An expression signature for $\mathrm{p} 53$ status in human breast cancer predicts mutation status, transcriptional effects, and patient survival. Proc Natl Acad Sci U S A 102(38):13550-13555.

52. Ivshina AV, George J, Senko O, Mow B, Putti TC, Smeds J, Lindahl T, Pawitan Y, Hall P, Nordgren H, Wong JE, Liu ET, Bergh J, et al. Genetic reclassification of histologic grade delineates new clinical subtypes of breast cancer. Cancer Res 2006;66(21):10292-10301.

53. Loi S, Haibe-Kains B, Desmedt C, Lallemand F, Tutt AM, Gillet C, Ellis P, Harris A, Bergh J, Foekens JA, Klijn JG, Larsimont D, Buyse M, et al. Definition of clinically distinct molecular subtypes in estrogen receptor-positive breast carcinomas through genomic grade. J Clin Oncol 2007;25(10):1239-1246.

54. Loi S, Haibe-Kains B, Desmedt C, Wirapati P, Lallemand F, Tutt AM, Gillet C, Ellis P, Ryder K, Reid JF, Daidone MG, Pierotti MA, Berns EM, et al. Predicting prognosis using molecular profiling in estrogen receptor-positive breast cancer treated with tamoxifen. BMC Genomics 
2008;9:239.

55. Loi S, Haibe-Kains B, Majjaj S, Lallemand F, Durbecq V, Larsimont D, Gonzalez-Angulo AM, Pusztai L, Symmans WF, Bardelli A, Ellis P, Tutt AN, Gillett CE, et al. PIK3CA mutations associated with gene signature of low mTORC1 signaling and better outcomes in estrogen receptor-positive breast cancer. Proc Natl Acad Sci U S A 2010;107(22):10208-10213.

56. Sotiriou C, Wirapati P, Loi S, Harris A, Fox S, Smeds J, Nordgren H, Farmer P, Praz V, Haibe-Kains B, Desmedt C, Larsimont D, Cardoso F, et al. Gene expression profiling in breast cancer: understanding the molecular basis of histologic grade to improve prognosis. J Natl Cancer Inst 2006;98(4):262-272.

57. Desmedt C, Piette F, Loi S, Wang Y, Lallemand F, HaibeKains B, Viale G, Delorenzi M, Zhang Y, d'Assignies MS, Bergh J, Lidereau R, Ellis P, et al. Strong time dependence of the 76-gene prognostic signature for node-negative breast cancer patients in the TRANSBIG multicenter independent validation series. Clin Cancer Res 2007;13(11):3207-3214.

58. Schmidt M, Böhm D, von Törne C, Steiner E, Puhl A, Pilch H, Lehr HA, Hengstler JG, Kölbl H and Gehrmann M. The humoral immune system has a key prognostic impact in node-negative breast cancer. Cancer Res 2008;68(13):54055413. 